\title{
Poly(amino acid)-grafted polymacrolactones. Synthesis, self-assembling and ionic coupling properties
}

\author{
E. Tinajero-Díaz ${ }^{1}$, A. Martínez de llarduya ${ }^{1}$, B. Cavanagh ${ }^{2}$ \\ A. Heise ${ }^{2}$, S. Muñoz-Guerra ${ }^{1^{*}}$ \\ 1Departament d’Enginyeria Química, Universitat Politècnica de Catalunya, ETSEIB, \\ Diagonal 647, 08028, Barcelona, Spain \\ ${ }^{2}$ Department of Chemistry, Royal College of Surgeons in Ireland, 123 St. Stephens \\ Green, Dublin 2, Ireland \\ *Corresponding author: sebastian.munoz@upc.edu
}

\begin{abstract}
Polyglobalide (PGI) with number average polymerization degree of $\sim 20$ was prepared by enzymatic ROP and then polyfunctionalized at $60 \%$ with aminothioethylene groups. The $\mathrm{PGI}_{20}-\left(\mathrm{NH}_{2}\right)_{12}$ copolymer was used as macroinitiator for the ROP of NCAs of BLG ( $\gamma$-benzyl L-glutamate) and ZLL $\left({ }^{\varepsilon} N\right.$-carbobenzoxy-L-lysine) protected amino acids to produce neutral polypeptide-grafted polyglobalides poly[ $\mathrm{Gl}_{20^{-}}$ graft- $\left.(A A)_{z}\right]$ with $z=5$ and 12 , which upon deprotection, afforded anionic and cationic copolymers, respectively. Both protected and deprotected graft copolymers were characterized in full detail by NMR, and their thermal properties were evaluated by TGA and DSC. The structure of these copolymers in the solid-state was examined by FTIR and XRD using synchrotron radiation. All grafted polyglobalides were amorphous but the polypeptide side chains were arranged in either alpha-helix or beta-sheet conformation, and reliable indications on the occurrence of supramolecular structures were frequently found. The capacity of poly[Gl $\mathrm{Gl}_{20}$-graft- $\left.(A A)_{z}\right]$ copolymers to selfassemble in aqueous medium was evidenced by the preparation of well-shaped spheroidal nanoparticles with a diversity of sizes depending on copolymer composition and charge. Loading and release of doxorubicin (DOX) from nanoparticles made of negatively charged poly[G| $\mathrm{G}_{20}$-graft-(LGA) $\left.{ }_{12}\right]$ as well as DNA complexation with cationic poly $\left.\left[\mathrm{Gl}_{20} \text {-graft-(LL) }\right)_{5}\right]$ were explored to appraise the potential of these copolymers for building drug delivery systems.
\end{abstract}




\section{Introduction}

In chemotherapy, polymeric nanoparticles and nanocapsules are unique systems able to carry drugs in vivo with release at a target site thereby minimizing negative side effects associated with a prolonged administration [1,2]. Polyesters in particular [3,4] and more recently poly(amino acid)s (PAA) [5-7], have been highlighted as promising vehicles for drug delivery controlled by external stimuli and mediated by polymer degradation.

Poly(amino acid)s (PAA) are attractive candidates for drug delivery because they are biocompatible, are easily available in a wide variety of chemical structures, and may adopt different regular molecular conformations depending on the environment. In addition, some amino acids are readily ionized to become either positively or negatively charged, a quality that makes PAA particularly suitable as stimuli-responsive materials [8-12]. PAA are commonly prepared by ROP of amino acid $\mathrm{N}$-carboxyanhydrides (AA NCA) [13]. On the other hand, aliphatic polyesters are mostly non-functional polymers without noticeable molecular activity. They are however susceptible to enzymatic degradation at a rate that depends on their hydrophilichydrophobic balance and display in general a good biocompatibility $[14,15]$. Polyesters are produced by well-known chemical procedures based on either direct polycondensation or ring-opening polymerization of lactones [16]. In fact, aliphatic polyesters are easily synthesized compared to other polycondensation polymers that usually need more severe polymerization conditions or/and entail monomers of much more difficult availability. Given the complementary properties of PAA and polyesters, their combination in the form of copolymers constitutes an attractive approach for the design of nanocarriers particularly suitable for controlled drug delivery $[17,18]$.

A fair assortment of linear block copolymers made of polypeptide and polyester blocks has been reported to date. Block polyester-polypeptide structures are usually obtained by ROP of the AA NCA initiated from an amino-capped polyester that was previously synthesized using a suitable functionalized initiator for the ROP of the 
lactone [13]. In most cases the polyester was generated from medium-size lactones (up to 11 atoms) such as $\varepsilon$-caprolactone (CL) and L-lactide (LA), and the homopolypeptide block was derived from different common amino acids such as Lglutamic acid, L-lysine, L-alanine, etc. [19-25]. Macrolactones (MLs), i.e. lactones consisting in 12 or more atoms, have recently emerged as a new family of building blocks for creating novel polymer functional materials [26]. The polyesters made of MLs have hydrophobic character comparable to paraffins and display a strong tendency to crystallize. Such features have motivated their use for the design of biodegradable nanoparticles and fibres suitable for drug dispensing applications including in several cases the loading and controlled delivery of doxorubicin (DOX) [27-30]. Despite the potential of MLs, only one example recently reported by us explored their marriage with PAA with the goal to render synergistic copolymer properties [31]. Block copolymers of $\omega$-pentadecalactone (PLA) and L-glutamic acid (LGA) or L-lysine (LL) with predetermined block lengths with the amino acids in either the free or protected form, were synthesized by sequential ROP. These copolymers were able to self-assemble in well-shaped nanospheres with a diameter in the $\sim 200-400 \mathrm{~nm}$ range and a negative zeta-potential.

Some combinations of PAA and polyester from medium size lactones for the design of amphiphilic graft copolymers have also been explored. Mostly the polyester chains were grafted onto the polypeptide backbone taking advantage of the functionality provided by amino acid side groups, as it is the case of PLL grafted with PLA [32,33]. Recently Thornton et al. [34] combined $N$-carboxyanhydride with $O$ carboxyanhydride ROP to synthesize poly(L-serine) grafted with a poly( $\alpha$-hydroxy acid). These copolymers were used to form nanoparticles capable of loading and subsequent releasing DOX via acid-mediated hydrolysis. Inverse structures consisting of the polyester backbone grafted with poly(amino acid)s are less accessible due to the lack of functionalization of the common polyesters. PLAs grafted with chains of L- 
alanine, L-aspartic acid or L-lysine have been prepared but in all these cases a copolymer of PLA containing minor amounts of Lys had to be used in a "grafting-from" approach $[35,36]$. The only example of PCL grafted with poly(amino acid)s was provided by Vert et al. [37], who reported (PCL-graft-PLL) copolymers that were synthesized following either the "grafting-onto" or the "grafting-from" method applied to a macropolycarbanionic PCL derivative.

Pendant functions may be readily introduced into polyesters via ROP of lactones bearing some functionality [38,39]. Globalide (GI) (oxacyclohexadecen-2-one) is a 16membered macrolactone that is widely used in perfumery. It is in fact a mixture of two different constitutional isomers with the double bond at the 11 or 12 position. As it is well known to happen with its saturated analogue PDL [40,41], GI readily polymerizes enzymatically or catalytically to produce polyglobalide (PGI), an unsaturated polyester that is semicrystalline $\left(T_{\mathrm{m}}=46^{\circ} \mathrm{C}\right)$ and non-cytotoxic [42]. The double bond present in the repeating unit of $\mathrm{PGl}$ has been used for thiol-ene addition reactions addressed to obtain cross-linked polymers, grafted copolymers and bioconjugates for drug loading [43-45].

In this work we have used PGI to prepare poly[(Gl-graft-(AA)] copolymers, specifically those made of L-glutamic acid (LGA) and L-lysine (LL) with their pendant function (carboxyl or amino) either protected or in the free form. The structure in the solid-state of these copolymers and their capability to self-assemble in nanoparticles when placed in aqueous media has been assessed. Finally, the potential of the ionic poly[Gl-graft-(LGA)] and poly[Gl-graft-(LL)] water soluble copolymers to load DOX and to condensate DNA has been explored. To our knowledge it is the first time that the synthesis, structure and properties of a polymacrolactone grafted with amino acids is reported. The use of $\mathrm{Gl}$ as building block has the remarkable advantage of providing inherent active groups suitable for ready functionalization and subsequent grafting. In addition the extremely high hydrophobicity of this lactone allows the design of systems with a sharp-edged amphiphilic nature and a satisfactory hidrophylic-hidrophobic 
balance. None of these advantages are profited when traditional short or medium-size lactones are used.

\section{Experimental section}

\subsection{Materials}

Triphosgene, $\alpha$-pinene, trifluoroacetic acid (TFA), 2-(Boc-amino)ethanethiol (BAET) (97\%), 2,2'-Azobis(2-methylpropionitrile) (AIBN) (98\%) were purchased from Sigma-Aldrich. $\mathrm{HBr}(33 \% \mathrm{w} / \mathrm{w}$ in acetic acid) from Alfa Aesar. $\gamma$-Benzyl-L-glutamate (BLG) and ${ }^{\varepsilon} N$-carbobenzoxy-L-lysine (ZLL) were purchased from Bachem. Anhydrous DMF (99.8\%), ethyl acetate (99.9\%) were used directly from the bottle under an inert atmosphere except toluene that was dried on $3 \AA$ molecular sieves. Globalide was provided by Grupo Indukern (Barcelona) and was dried over molecular sieves and Novozyme 435 (Candida antarctica Lipase B immobilized on cross-linked polyacrylate beads) was a gift of Novozymes (Denmark) and it was dried at $40{ }^{\circ} \mathrm{C}$ for 24 under vacuum. $\mathrm{DOX} \cdot \mathrm{HCl}(98 \%)$ and 1,1,1,3,3,3-hexafluoro-2-propanol (HFIP) were purchased from Apollo Scientific, (UK).

\subsection{Physico-chemical characterization}

${ }^{1} \mathrm{H}$ and ${ }^{13} \mathrm{C}$ NMR spectra were recorded on a Bruker AMX-300 spectrometer at 25 ${ }^{\circ} \mathrm{C}$, operating at 300.1 and $75.5 \mathrm{MHz}$, respectively, from samples dissolved in deuterated chloroform $\left(\mathrm{CDCl}_{3}\right)$ or a mixture of $\mathrm{TFA} / \mathrm{CDCl}_{3}$, and spectra were internally referenced to tetramethylsilane (TMS). About 10 and $50 \mathrm{mg}$ of sample in $1 \mathrm{~mL}$ of solvent were used for ${ }^{1} \mathrm{H}$ and ${ }^{13} \mathrm{C}$ NMR, respectively. Sixty-four scans were recorded for ${ }^{1} \mathrm{H}$, and between 1000 and 10,000 scans for ${ }^{13} \mathrm{C}$ NMR. (ATR) FTIR measurements were performed on a Perkin-Elmer spectrophotometer. Spectra were obtained from 8 scans in the spectral region of $450-4000 \mathrm{~cm}^{-1}$ with a resolution of $4 \mathrm{~cm}^{-1}$.

Molecular weights were evaluated by GPC on a Waters equipment provided with $\mathrm{RI}$ and UV detectors and using HFIP as eluent. $100 \mu \mathrm{L}$ of $0.1 \%(\mathrm{w} / \mathrm{v})$ sample solution in 
the same solvent were injected and chromatographed under a flow of $0.4 \mathrm{~mL} \mathrm{~min}^{-1}$. HR5E and HR2 Waters linear Styragel columns $\left(7.8 \mathrm{~mm} \times 300 \mathrm{~mm}\right.$, pore size $10^{3}-10^{4}$ A) packed with crosslinked polystyrene and protected with a pre-column were used. Molar mass average and distributions were calculated against PMMA standards.

Thermogravimetric analysis was performed on a Mettler-Toledo TGA/DSC 1 Star System under a nitrogen flow of $20 \mathrm{~mL} \mathrm{~min}^{-1}$ at a heating rate of $10 \stackrel{\circ}{\circ} \mathrm{C} \mathrm{min}-1$ and within a temperature range of $35-600^{\circ} \mathrm{C}$. The thermal behavior of the polymers was examined by differential scanning calorimetry (DSC), using a Perkin-Elmer DSC 8000 apparatus. Thermograms were obtained from 4-6 mg samples at heating and cooling rates of $10 \stackrel{\circ}{\circ} \min ^{-1}$ under a nitrogen flow of $20 \mathrm{~mL} \mathrm{~min}^{-1}$. Indium and zinc were used as standards for temperature and enthalpy calibration. Dynamic light scattering studies (DLS) were performed using a Zetasizer Nano ZS series Malvern instrument equipped with a $4 \mathrm{~mW}$ He-Ne laser operated at a wavelength of $633 \mathrm{~nm}$. Samples were placed in disposable cuvettes at $25 \stackrel{\circ}{\circ}$. The non-invasive back-scatter optic arrangement was used in order to collect the light scattered by the particles at an angle of $173^{\circ}$.

Real time X-ray diffraction studies were carried out using X-ray synchrotron radiation at the BL11 beamline (non-crystalline diffraction, NCD), at ALBA (Cerdanyola del Vallés, Barcelona, Spain). WAXS and SAXS spectra were recorded simultaneously from powder samples placed between aluminum foils and subjected to heating-cooling cycles at rates of $10{ }^{\circ} \mathrm{C} \mathrm{min}^{-1}$. The radiation energy employed corresponded to a 0.10 $\mathrm{nm}$ wavelength, and spectra were calibrated with silver behenate $(\mathrm{AgBh})$ and $\mathrm{Cr}_{2} \mathrm{O}_{3}$. Transmission Electron Microscopy (TEM) images were recorded on a Hitachi 7650 microscope working at $120 \mathrm{kV}$. Samples were prepared by spraying a $1 \mathrm{~g} \cdot \mathrm{L}^{-1}$ solution of the copolymer onto a copper grid (200 mesh, carbon coated), dripping the water excess, and applying negative staining with an $1 \%$ uranyl acetate aqueous solution 


\subsection{Synthesis}

\subsubsection{N-carboxyanhydrides (NCA)s.}

$\gamma$-Benzyl-L-glutamate (BLG) and ${ }^{\varepsilon} N$-carbobenzoxy-L-lysine (ZLL) NCAs were synthesized following literature procedures [46,47].

\subsubsection{Poly[GI $\left.{ }_{8}-\mathrm{Co}-\left(\mathrm{GINH}_{2}\right)_{12}\right]$ macroinitiator}

Polyglobalide $\left(\mathrm{PGI}_{20}\right)$. Novozyme $435(0.44 \mathrm{~g})$ was dried in a Schlenk flask at $40{ }^{\circ} \mathrm{C}$ in a desiccator overnight. Globalide $(2.1 \mathrm{~g})$ and dried toluene $(4.0 \mathrm{~mL})$ were then added to the reaction flask which was purged with nitrogen gas and heated in an oil bath at 60 ${ }^{\circ} \mathrm{C}$ for four hours. Dichloromethane (DCM) was then added to dissolve the reaction product and inhibit the enzyme activity. The polyester was isolated from the filtered solution by precipitation into ice-cold methanol and dried overnight. Yield: 97\%.

Poly[Gl $\mathbf{G}_{8}$-co-(GINH$\left.)_{2}\right)_{12}$. Polyglobalide $(0.2 \mathrm{~g})$ and 2-(Boc-amino)ethanethiol $(1.11 \mathrm{~g})$ were weighed into a Schlenk tube together with AIBN (50 mg). $1 \mathrm{~mL}$ of THF was then added and the mixture purged with nitrogen gas. The reaction was commenced by immersing it into an oil bath at $80 \stackrel{\circ}{\circ}$ under agitation provided by a magnetic stirrer. The reaction was allowed to run for $24 \mathrm{~h}$ and was terminated by addition of DCM to the reaction mixture immersed in an ice bath. The mixture was precipitated in cold methanol and the copolymer recovered by centrifugation. The obtained poly[globalideco-2-(Boc-amino)ethyl-thio globalide)] was dissolved in DCM and reprecipitated. Yield: $90 \%$.

Removal of Boc from the 2-(Boc-amino)ethylthio side groups was made by treatment with TFA. A solution of the protected copolyester $(100 \mathrm{mg})$ in $2 \mathrm{~mL}$ of TFA was stirred at room temperature for $3 \mathrm{~h}$. Then, the solution was added to $30 \mathrm{~mL}$ of diethyl ether and the amino-free poly[ $\left.\mathrm{Gl}_{8}-\mathrm{CO}-\left(\mathrm{GINH}_{2}\right)_{12}\right]$ copolymer was separated by centrifugation, washed twice with saturated $0.5 \mathrm{M}$ aqueous $\mathrm{NaHCO}_{3}$, and finally dried under vacuum at RT. Yield: $90 \%$. 


\subsubsection{Synthesis of protected poly $\left[\mathrm{GI}_{20}-\mathrm{graft}-(\mathrm{AA})_{\mathrm{z}}\right]$ copolymers}

Poly[globalide-graft-( $\gamma$-benzyl-L-glutamate) $)_{z}$ (Poly[GI ${ }_{20}$-graft-(BLG) $\left.)_{z}\right)$. In a Schlenk tube, BLG-NCA (124 mg, $0.468 \mathrm{mmol}$ or $200 \mathrm{mg}, 0.760 \mathrm{mmol}$ for $\mathrm{z}=5$ or 12) was dissolved in $6 \mathrm{~mL}$ anhydrous DMF and placed in a water- $\mathrm{NaCl}$ bath. A solution of poly[Gl $\left.\mathrm{Gl}_{8}-\mathrm{Co}-\left(\mathrm{GINH}_{2}\right)_{12}\right](36 \mathrm{mg}, 0.0063 \mathrm{mmol}$ or $25 \mathrm{mg}, 0.0043 \mathrm{mmol}$ for $\mathrm{z}=5$ or 12 , respectively) in $2 \mathrm{~mL}$ anhydrous DMF was injected through a rubber septum with a syringe. The reaction was left under stirring for 5 days and then it was precipitated into an excess of cold diethyl ether, recovered by centrifugation and dried under vacuum. Yield: $80 \%$.

Poly[globalide-graft-( $N^{\varepsilon}$-carbobenzoxy-L-lysine $\left.)_{z}\right] \quad\left(\right.$ Poly $_{G^{\prime}} \mathrm{G}_{20}-$ graft-(ZLL) $\left.]\right) \quad$ was synthesized in a similar fashion as poly[Gl ${ }_{20}-$ graft-(BLG) $\left.)_{z}\right]$ with a yield of $80 \%$.

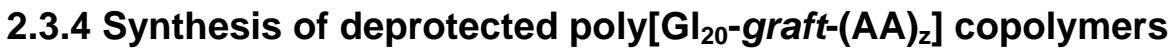

Poly[G| ${ }_{20}$-graft-(LGA) $]$ For removal the benzyl group from poly[Gl ${ }_{20}$-graft-(BLG) $\mathrm{z}, 150$ $\mathrm{mg}$ of copolymer were dissolved in $1 \mathrm{~mL}$ of TFA. Then a solution of $\mathrm{HBr}$ in glacial acetic acid ( 2.5 or 5 times excess with respect to polypeptide) was added slowly to the copolymer solution at $0{ }^{\circ} \mathrm{C}$ and after standing $3 \mathrm{~h}$ the solution was poured into an excess of diethyl ether. The precipitate was recovered by centrifugation, washed twice with diethyl ether, and dissolved in a $0.5 \mathrm{M} \mathrm{NaHCO}_{3}$ aqueous solution to have the polymer in the sodium salt form. The basic solution was dialyzed against distilled water (MWCO $2.0 \mathrm{kDa}$ ) for $12 \mathrm{~h}$ at room temperature and dried under vacuum to render poly $\left[\mathrm{Gl}_{20}\right.$-graft-(LGA) $]$ as a white solid. Yield: $80 \%$.

Poly[GI ${ }_{20}-$ graft-(LL) $\mathbf{z}$ was obtained by applying the same procedure to poly[Gl-graft(ZLL) z]. Yield: $75 \%$..

\subsection{Nanoparticles preparation and drug loading and releasing studies}

2.4.1 Nanoparticles (NPs) preparation. The nanoprecipitation method was applied to

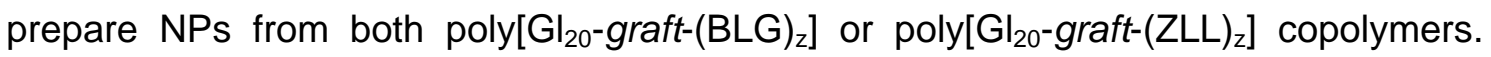
Briefly, $5 \mathrm{mg}$ of copolymer were dissolved in $1.5 \mathrm{~mL}$ of DMF at room temperature. 
Then, $3 \mathrm{~mL}$ of deionized water were added dropwise into the solution under vigorous magnetic stirring (300 rpm). To remove DMF the solution was transferred to a dialysis tube (MWCO $3.5 \mathrm{kDa}$ ) and dialyzed against $0.5 \mathrm{~L}$ of deionized water for $24 \mathrm{~h}$ with replacement of the dialyzing medium every $5 \mathrm{~h}$. The same method was used for preparing NPs from deprotected copolymers poly[ $\left[\mathrm{Gl}_{20}-\right.$ graft-(LGA) $]$ and poly $\left[\mathrm{Gl}_{20}\right.$-graft$(L L)_{z}$. In this case $3 \mathrm{mg}$ of copolymer were dissolved in $1 \mathrm{~mL}$ of HFIP). Then $3 \mathrm{~mL}$ of deionized water were added and left under magnetic stirring at room temperature until HFIP evaporated completely. The ionotropic gelation method was used to form polyplexes derived from stoichiometric mixtures of poly[G| ${ }_{20}$-graft-(LGA) $]$ and poly $\left[\mathrm{Gl}_{20^{-}}\right.$ graft-(LL) $)_{z}$ copolymers. Complexes NPs were prepared by adding drop-wise the poly $\left[\mathrm{Gl}_{20}-\right.$ graft- $\left.(\mathrm{LL})_{\mathrm{z}}\right]$ solution $\left(1.5 \mathrm{mg} \cdot \mathrm{mL}^{-1}\right)$ to that containing poly[G| $\mathrm{Gl}_{20}$-graft-(LGA) $\left.{ }_{\mathrm{z}}\right](5$ $\left.\mathrm{mg} \cdot \mathrm{mL}^{-1}\right)$. In the all three methods the NPs aqueous suspension finally obtained was used for DLS measurements and TEM observations.

\subsubsection{Drug loading}

Poly[Gl $\mathrm{G}_{20}$-graft-(LGA) $)(5 \mathrm{mg})$ was placed in deionized water $(4 \mathrm{~mL})$ and stirred for 10 min until complete dissolution. $1 \mathrm{~mL}$ solutions of $\mathrm{DOX} \cdot \mathrm{HCl}$ in deionized water at different concentrations ( 1 to $5 \mathrm{mg} \cdot \mathrm{mL}^{-1}$ ) were prepared and added dropwise with a syringe into the copolymer solution and the mixture left under stirring overnight. Excess drug was removed by dialysis (MWCO 2,000, Spectrum Labs) against distilled water for $24 \mathrm{~h}$ (the dialysis medium was replaced intermittently). Loaded NPs were characterized by DLS and SEM/TEM. Drug-Loading Efficiency (DLE) and DrugLoading Content (DLC) were estimated from ${ }^{1} \mathrm{H}$ NMR data by using the following equations:

$$
\text { DLE } \%=\frac{\text { Mass of the drug in NPs }}{\text { Mass of the drug in feed }} 100 \quad \text { DLC } \%=\frac{\text { Mass of drug in NPs }}{\text { Mass of NPS }} 100
$$




\subsubsection{Drug releasing}

Drug releasing was studied at two pHs (PBS, pH 7.4 and citrate-phosphate, $\mathrm{pH}$ 4.2). DOX.poly[Gl ${ }_{20}$-graft-(LGA) $]$ NPs suspension in each buffer $(2.5 \mathrm{~mL})$ was placed in a dialysis tube (MWCO 6000-8000, Spectrum Labs) and placed in $25 \mathrm{~mL}$ of the same buffer under mild stirring at $37^{\circ} \mathrm{C}$. At scheduled time intervals, $1.5 \mathrm{~mL}$ aliquots of the release medium was taken out and replenished with an equal volume of fresh medium. The amount of released DOX was determined by measuring the absorbance of the withdrawn aliquots at $480 \mathrm{~nm}$ in a UV-vis spectrophotometer Cecil Aurius Series CE 2021.

\section{Results and Discussion}

\subsection{Synthesis of polypeptide-grafted poly(globalide)s}

The pathway followed in this work to synthesize the polypeptide-grafted poly(globalide)s, abbreviated as poly[Gl $\mathrm{Gl}_{20}$ graft- $\left.(\mathrm{AA})_{z}\right]$ where AA is $\gamma$-benzyl L-glutamate (BLG)/L-glutamic acid (LGA) or ${ }^{\varepsilon} N$-carbobenzoxy L-lysine (ZLL)/(L-lysine (LL), and the $z$ subscript stands for the average number of amino acid units in the grafting polypeptide chains, is depicted in Scheme 1. The results of these syntheses including the compositions and molecular weights of both intermediate and final copolymers are collected in Table 1.

Firstly the polyamine macroinitiator poly $\left[\left(\mathrm{Gl}_{8}-\mathrm{CO}-\left(\mathrm{GINH}_{2}\right)_{12}\right]\right.$ was synthesized. The PGI sample used for this synthesis was obtained with an average length of 20 units $\left(M_{n}\right.$ $\sim 4750 \mathrm{~g} \cdot \mathrm{mol}^{-1}$ ) by enzymatic ROP of globalide. Amine polyfunctionalization of PGI was accomplished by thiol-ene reaction with 2-(Boc-amino)ethanethiol (BAET) catalyzed by AIBN. The minimum amount of solvent necessary to enable complete reactants miscibility was used in order to maximize conversion [48]. The amount of BAET that became inserted in the $\mathrm{PGI}_{20}$ chain was measured by ${ }^{1} \mathrm{H}$ NMR. The relative remaining 


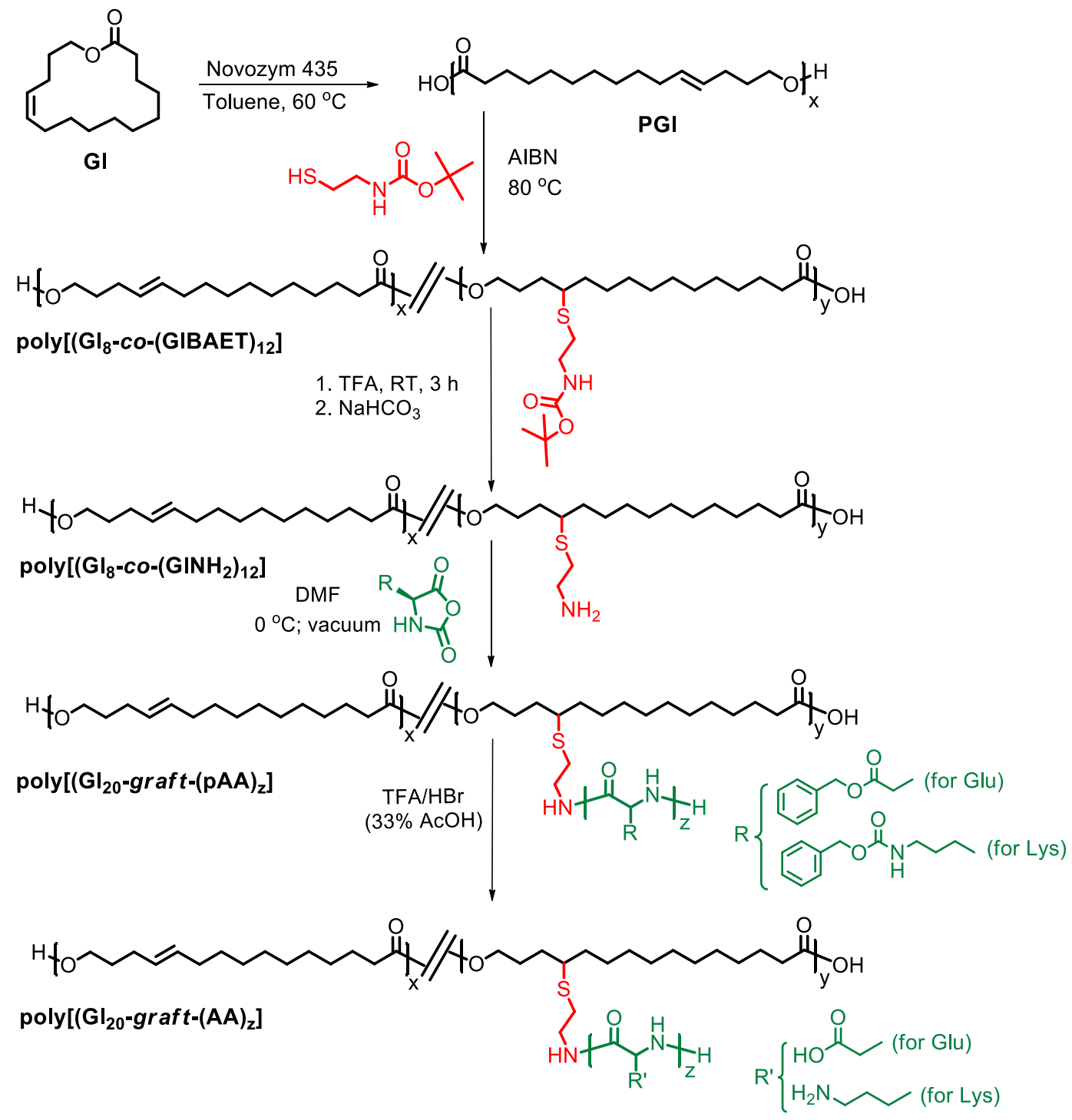

Scheme 1. Synthesis of poly $\left[\left(\mathrm{Gl}_{20}\right.\right.$-graft- $\left.(\mathrm{AA})_{z}\right]$ copolymers. Only the 11-ene isomer of $\mathrm{Gl}$ is represented for simplicity.

area of the signal arising from the double bond protons at around $5.4 \mathrm{ppm}$ indicated that $60 \%$ of the Gl units were modified. Removal of the Boc group by treatment with TFA led to the random copolyester poly[ $\left(\mathrm{Gl}_{8}-\mathrm{CO}-\left(\mathrm{GINH}_{2}\right)_{12}\right]$ which was then used as macroinitiator for amino acid grafting. The ${ }^{1} \mathrm{H}$ NMR spectra of initial $\mathrm{PGl}_{20}$, the BAET-modified $\mathrm{PGI}_{20}$ and the multifunctionalized macroinitiator are shown in Figure S1 of the Supporting Information file (SI). 
Table 1. Results of the synthesis of poly[Gl $\mathrm{Gl}_{20}$-graft-(AA) $\left.{ }_{z}\right]$ copolymers.

\begin{tabular}{|c|c|c|c|c|c|c|c|}
\hline Polymer & $\begin{array}{c}\text { Feed }^{\mathrm{c}} \\
{\left[\mathrm{NH}_{2}\right] /[\mathrm{NCA}]}\end{array}$ & $\begin{array}{l}\text { Yield } \\
(\%)\end{array}$ & $\begin{array}{c}M_{n}^{\mathrm{d}} \\
\left(\mathrm{g} \cdot \mathrm{mol}^{-1}\right)\end{array}$ & $\begin{array}{c}M_{n}^{\mathrm{e}} \\
\left(\mathrm{g} \cdot \mathrm{mol}^{-1}\right)\end{array}$ & $\boldsymbol{\theta}^{e}$ & $\begin{array}{l}\text { Composition }^{\dagger} \\
{[\mathrm{Gl}] /[\mathrm{AA}]}\end{array}$ & $\begin{array}{c}\text { Grafted Gl }^{9} \\
(\%)\end{array}$ \\
\hline $\mathrm{PGI}_{20}$ & - & 97 & 4750 & - & - & - & - \\
\hline \multicolumn{8}{|l|}{ Poly[GI $\left.{ }_{8}-\mathrm{co}-(\mathrm{TGI})_{12}\right]^{\mathrm{a}}$} \\
\hline $\begin{array}{l}\text { Poly }\left[\mathrm{GI}_{8}-\mathrm{co}-(\mathrm{GIBAET})_{12}\right] \\
\left.\text { Poly[G| }\left.\right|_{8}-\mathrm{Co}-\left(\mathrm{GINH}_{2}\right)_{12}\right]\end{array}$ & $\begin{array}{l}- \\
-\end{array}$ & $\begin{array}{l}90 \\
90\end{array}$ & $\begin{array}{l}6880 \\
5680\end{array}$ & $\begin{array}{l}7430 \\
5500\end{array}$ & $\begin{array}{l}2.2 \\
2.6\end{array}$ & $\begin{array}{l}- \\
-\end{array}$ & $\begin{array}{l}- \\
-\end{array}$ \\
\hline \multicolumn{8}{|l|}{ Poly $\left[\mathrm{GI}_{20} \text {-graft-(AA) }\right]^{\mathrm{b}}$} \\
\hline $\begin{array}{l}\left.\text { Poly }\left[\mathrm{GI}_{20} \text {-graft-(BLG) }\right)_{5}\right] \\
\text { Poly }\left[\mathrm{GI}_{20^{-}} \text {graft-(BLG) }{ }_{12}\right]\end{array}$ & $\begin{array}{c}1 / 6 \\
1 / 15\end{array}$ & $\begin{array}{l}80 \\
79\end{array}$ & $\begin{array}{l}16,850 \\
35,690\end{array}$ & $\begin{array}{l}13,600 \\
14,500\end{array}$ & 3.0 & $\begin{array}{l}27 / 73 \\
12 / 88\end{array}$ & $\begin{array}{l}60 \\
60\end{array}$ \\
\hline $\begin{array}{l}\left.\text { Poly }\left[\mathrm{Gl}_{20}-\text { graft-(ZLL) }\right)_{5}\right] \\
\left.\text { Poly }\left[\mathrm{Gl}_{20} \text {-graft-(ZLL) }\right)_{12}\right]\end{array}$ & $\begin{array}{c}1 / 5 \\
1 / 12\end{array}$ & $\begin{array}{l}80 \\
83\end{array}$ & $\begin{array}{l}20,090 \\
40,000\end{array}$ & $\begin{array}{l}11,200 \\
25,600\end{array}$ & 2.2 & $\begin{array}{l}26 / 74 \\
13 / 87\end{array}$ & $\begin{array}{l}60 \\
60\end{array}$ \\
\hline $\begin{array}{l}\left.\text { Poly }\left[G_{20} \text {-graft-(LGA) }\right)_{5}\right] \\
\left.\text { Poly }\left[\left.G\right|_{20} \text {-graft-(LGA) }\right)_{12}\right]\end{array}$ & $\begin{array}{c}1 / 6 \\
1 / 15\end{array}$ & $\begin{array}{l}50 \\
60\end{array}$ & $\begin{array}{l}12,260 \\
27,350\end{array}$ & $\begin{array}{c}2000 \\
10,300\end{array}$ & $\begin{array}{l}1.6 \\
1.6\end{array}$ & $\begin{array}{l}27 / 73 \\
12 / 88\end{array}$ & $\begin{array}{l}60 \\
60\end{array}$ \\
\hline $\begin{array}{l}\left.\left.\text { Poly[GI }{ }_{20} \text {-graft-(LL) }\right)_{5}\right] \\
\text { Poly }\left[\mathrm{Gl}_{20} \text {-graft-(LL) }{ }_{12}\right]\end{array}$ & $\begin{array}{c}1 / 5 \\
1 / 12\end{array}$ & $\begin{array}{l}75 \\
75\end{array}$ & $\begin{array}{l}12,720 \\
22,450 \\
\end{array}$ & $\begin{array}{l}8200 \\
8000\end{array}$ & $\begin{array}{l}1.7 \\
2.2\end{array}$ & $\begin{array}{l}26 / 74 \\
13 / 87\end{array}$ & $\begin{array}{l}60 \\
60\end{array}$ \\
\hline
\end{tabular}

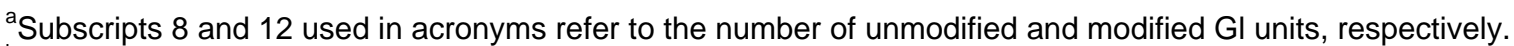

${ }^{b}$ Subscript 20 used in acronyms refers to the total number of $\mathrm{Gl}$ units in the polyester chain and subscript $z$ (taking 5 or 12 values) refers to the average number of amino acids contained in the polypeptide side chains.

${ }^{\circ}$ Molar ratio of amine groups to AA NCA in the feed.

${ }^{\mathrm{d}}$ Number-average molecular weight determined by ${ }^{1} \mathrm{H}$ NMR.

Number-average molecular weight and molar dispersities determined by GPC.

${ }^{f}$ Globalide to amino acid units ratio present in the graft copolymers.

${ }^{9}$ Percentage of grafted Gl units in the graft copolymers.

L-Glutamic acid and L-lysine were selected as amino acids for the grafting due to their anionic and cationic character, respectively. The "grafting-from" procedure was accomplished by ROP of the $\mathrm{N}$-carboxyanhydrides of the two protected amino acids, i.e. as $\gamma$-benzyl ester and ${ }^{\varepsilon} N$-carbobenzyl benzoxy, respectively, from the amino groups present in poly[$\left[\left(\mathrm{Gl}_{8}-\mathrm{Co}-\left(\mathrm{GINH}_{2}\right)_{12}\right]\right.$. These reactions were performed in $\mathrm{DMF}$ at $0{ }^{\circ} \mathrm{C}$ to avoid end-group termination and minimize side-reactions [47]. Subsequently, full removal of the $\mathrm{Bn}$ and $\mathrm{Z}$ protecting groups was attained by treatment with $\mathrm{TFA} / \mathrm{HBr}$ without apparent alteration of the polyester backbone, as ascertained by NMR. This result is according to expectations since the benzyl group is better released than the alkyl group, and its location on the side chain is much more accessible to water. Furthermore the high hydrophobic character of the hydrocarbon chain of GI must shield 
the backbone ester group to the attack of external reagents. Regarding the $Z$ group, the high sensitivity of the carbamate group to hydrolysis will be enough to account for its specific removal. Nevertheless the same arguments relatives to group accessibility

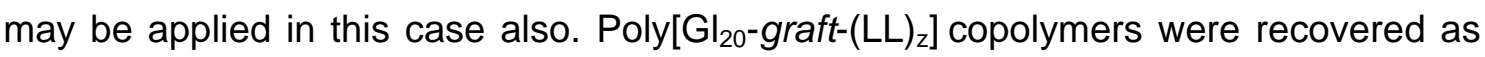
hydrobromide salts whereas poly[Gl $\mathrm{Gl}_{20}$-graft- $\left.(\mathrm{LGA})_{z}\right]$ copolymers were converted in their sodium salts for a more convenient handling.

${ }^{1} \mathrm{H}$ and ${ }^{13} \mathrm{C}$ NMR analyses were used to follow the grafting process and determine the copolymer molecular weights, and a representative selection of the spectra recorded from the graft copolymers is provided in Figures 1 and 2 and Figure $\mathrm{S} 2$ in the $\mathrm{SI}$ file. ${ }^{1} \mathrm{H}$ NMR signals arising from the $\underline{\mathrm{C}} \mathrm{H}_{2}-\mathrm{OH}$ end-groups were quantitatively compared with signals arising from internal methylenes to determine the number of Gl units in PGI $(\sim 20)$ corresponding to a $M_{n} \approx 4750 \mathrm{~g} \cdot \mathrm{mol}^{-1}$. The grafting reaction was evidenced by the new signals appearing on the PGI spectrum in the 4.44.6 ppm range that are attributable to the $\alpha$-proton of the inserted poly(amino acid) segment. Moreover, the protons of the methylene directly attached to the amino group $\left(\mathrm{C}_{2}-\mathrm{NH}\right)$ in the thioethylene spacer are downfield shifted down to $3.5 \mathrm{ppm}$ due to the formation of the amide bond. Such signal (d), which appears split into two broad multiplets due to the asymmetric carbon of the amino acid residue, is shared by all copolymers and it provides evidence of the successful attachment of amino acids to the PGI main chain via NCA ROP. By comparing the intensity of protons " $d$ " with the intensity of protons " $\alpha$ " is possible to assess the average degree of polymerization attained in the polypeptide side chains which were calculated to be around 5 and 12 . Furthermore, since no signal arising from the $\mathrm{CH}_{2}-\mathrm{NH}_{2}$ was detected in the grafted copolymers it is concluded that all amino side groups in the poly[ $\left[\mathrm{Gl}_{8}-\mathrm{Co}-\left(\mathrm{GINH}_{2}\right)_{12}\right]$ had reacted so the grafting degree was estimated to be $60 \%$ in every case. 
a)
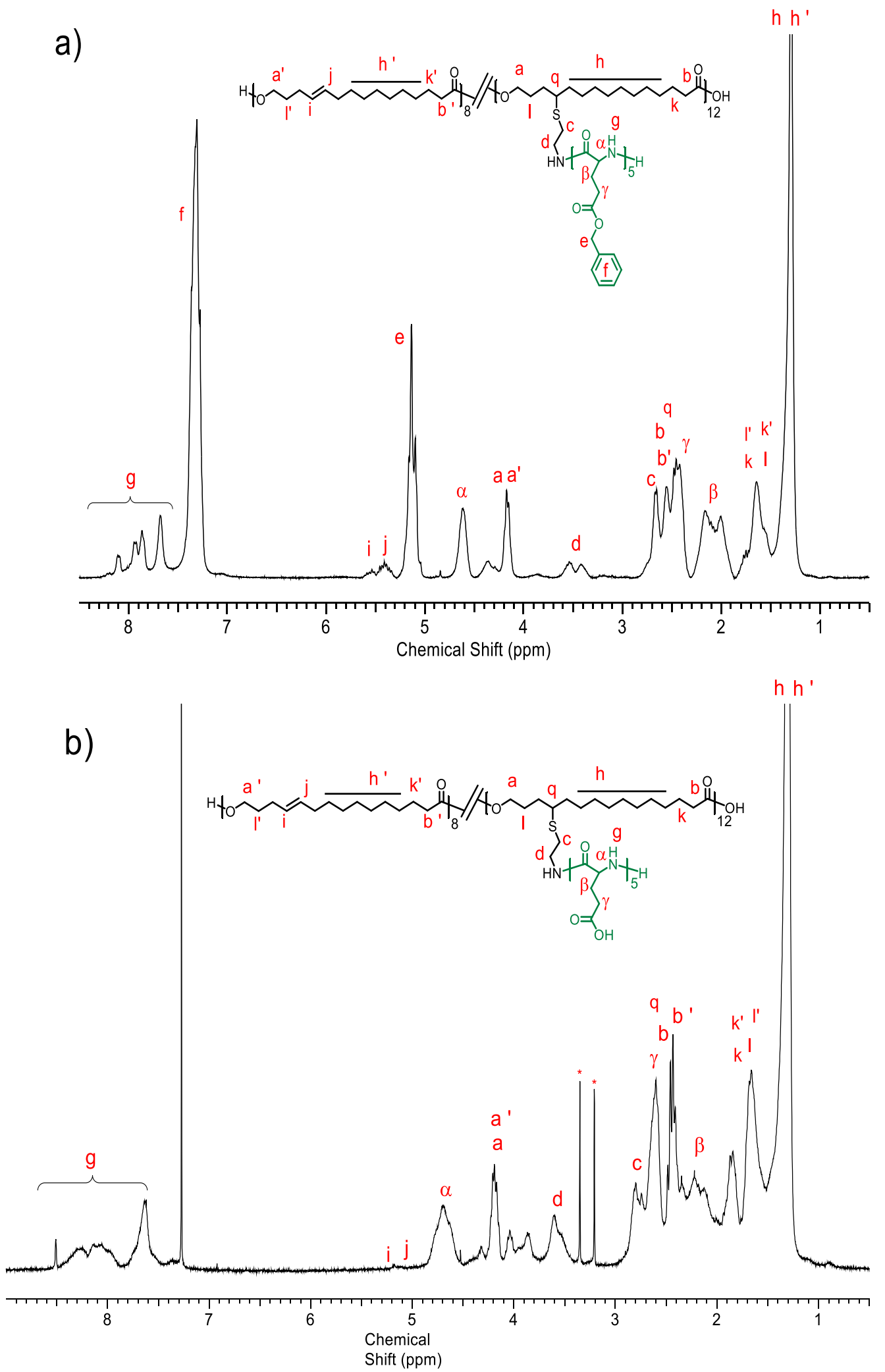

Figure 1. ${ }^{1} \mathrm{H} \mathrm{NMR}\left(\mathrm{CDCl}_{3} / \mathrm{TFA}\right)$ spectra of: (a) poly[Gl ${ }_{8}$-graft-(BLG) $\left.)_{5}\right]$ and (b) poly $\left[\mathrm{Gl}_{20}\right.$-graft$(\mathrm{LGA})_{5}$ ] copolymers. 
a)

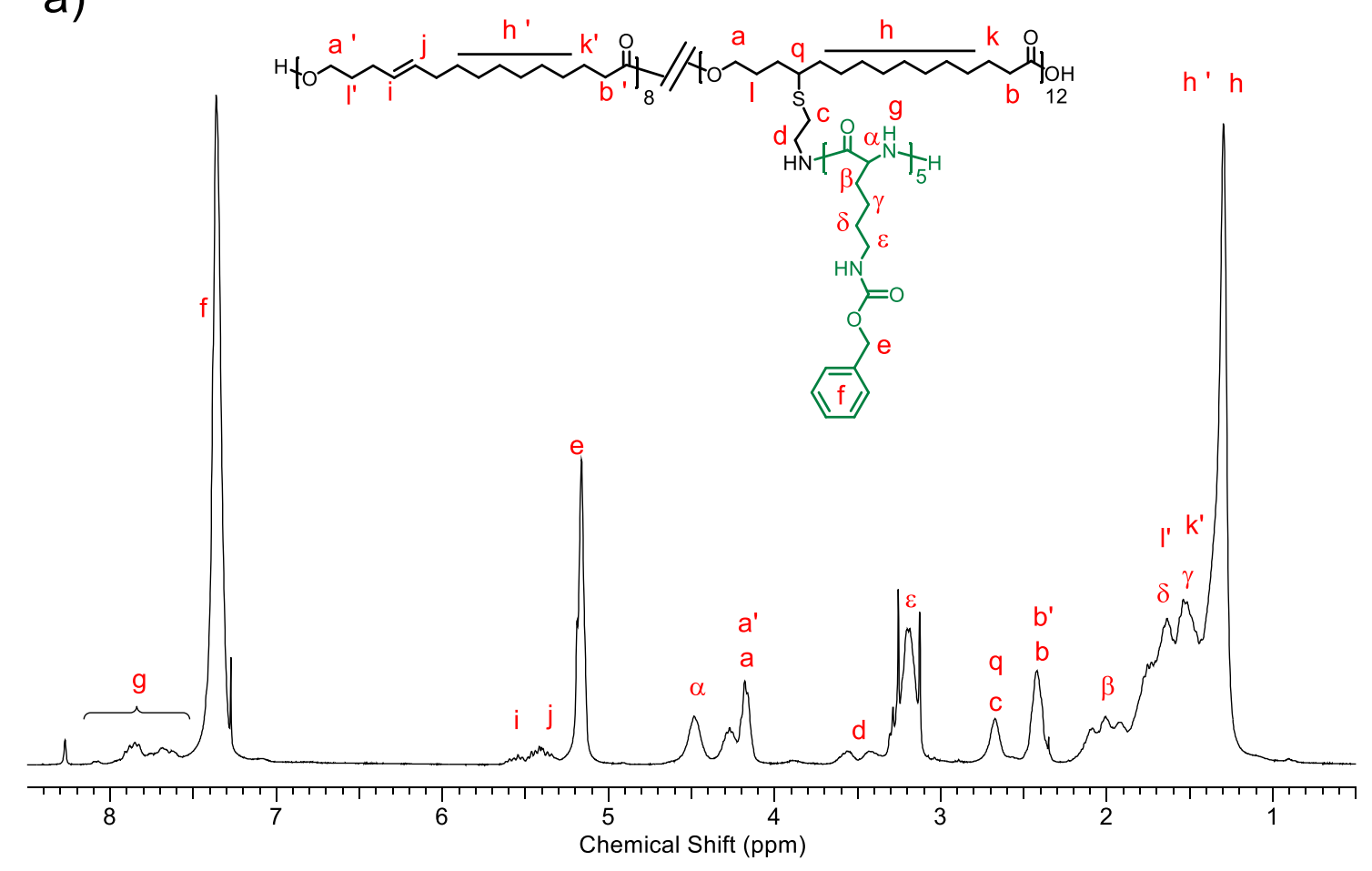

b)

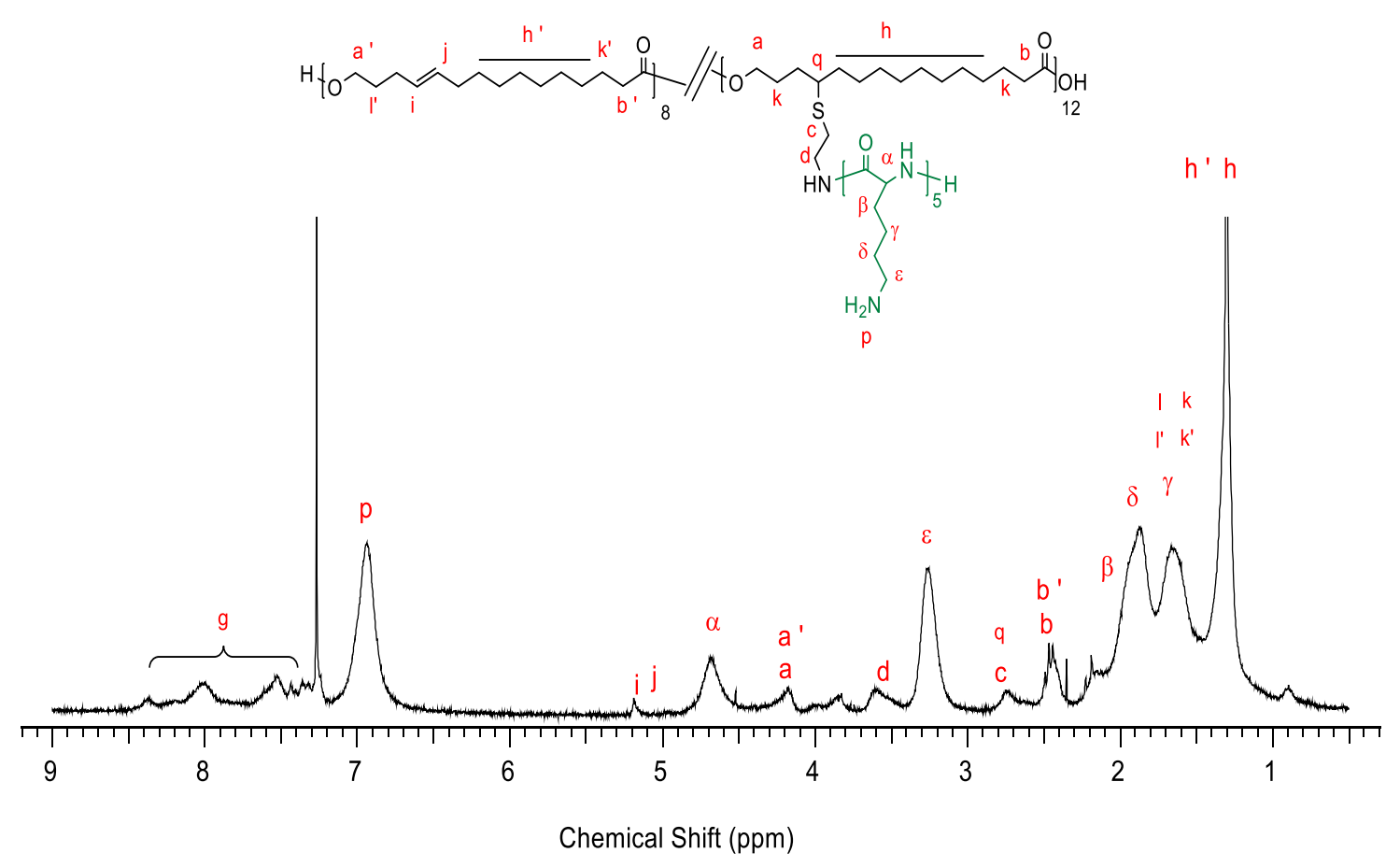

Figure 2. ${ }^{1} \mathrm{H}$ NMR $\left(\mathrm{CDCl}_{3} / \mathrm{TFA}\right)$ spectra of: (a) poly[Gl ${ }_{20}$-graft-(ZLL) $\left.)_{5}\right]$ and (b) poly $\left[\mathrm{Gl}_{20}\right.$-graft$(\mathrm{LL})_{5}$ ] copolymers. 
GPC of the intermediate and final copolymers showed monomodal peaks supporting the absence of homopolypeptide species in the graft copolymers (Figure S3 in the SI file) highlighting that the PAA was indeed grafted to the PGI. A good agreement was found between the $M_{n}$ values determined by ${ }^{1} \mathrm{H}$ NMR and GPC as far as the ungrafted copolymers where concerned whereas significant discrepancies appeared after grafting. Such discrepancies may be at least in part explained by the differences in hydrodynamic volume between the grafted copolymers and the PMMA used as standard. It should also be noted that similar inconsistencies have been reported before for other polyester-polypeptide copolymers and attributed to the occurrence of specific interactions between the chromatography filler and the polypeptide moiety of the copolymer [23,49].

\subsection{Thermal properties}

The thermal properties of all copolymers were examined by TGA and DSC and the most relevant parameters are collected in Table 2. The TGA traces and their derivative curves are shown in Figures S4 and S5 of the SI file. Upon heating polyglobalide starts to decompose at $370 \stackrel{\circ}{ } \mathrm{C}$ showing a sharply decay in weight at 420 ${ }^{\circ} \mathrm{C}$ with less than $2 \%$ of material remaining at $600 \stackrel{\circ}{\circ}$. Grafted copolymers showed a considerable decrease in thermal stability and their TGA profiles are complex indicating the occurrence of several decomposition steps as it could be expected from the presence of the polypeptide counterpart.

At clear difference with PGI, none of the graft copolymers displayed melting by DSC, as it could be largely expected from their non-regular branched architecture (Figure 3). The only heat exchange observed on DSC traces was a weak broad endotherm located at temperatures around 113-119 ${ }^{\circ} \mathrm{C}$ for the BLG-grafted copolymers which could not be reproduced at the second heating. A peak with similar 
Table 2. Thermal properties of poly $\left[\mathrm{Gl}_{20}-\right.$ graft- $\left.(A A)_{z}\right]$ copolymers.

\begin{tabular}{|c|c|c|c|c|c|c|c|c|c|c|c|}
\hline & \multicolumn{3}{|c|}{ TGA $^{\mathrm{a}}$} & \multicolumn{8}{|c|}{ DSC $^{b}$} \\
\hline & \multirow[b]{2}{*}{$\begin{array}{l}{ }^{\circ} T_{d} \\
\left({ }^{\circ} \mathrm{C}\right)\end{array}$} & \multirow[b]{2}{*}{$\begin{array}{c}{ }^{\max } T_{d} \\
\left({ }^{\circ} \mathrm{C}\right)\end{array}$} & \multirow[b]{2}{*}{$\begin{array}{l}R_{w} \\
(\%)\end{array}$} & \multicolumn{5}{|c|}{ First heating } & \multicolumn{3}{|c|}{ Second heating } \\
\hline & & & & $\begin{array}{c}T_{g} \\
\left({ }^{\circ} \mathrm{C}\right)\end{array}$ & $\begin{array}{c}T_{m} \\
\left({ }^{\circ} \mathrm{C}\right)\end{array}$ & $\begin{array}{c}\Delta H \\
\left(\mathrm{~J} \cdot \mathrm{g}^{-1}\right.\end{array}$ & $\begin{array}{l}T_{L C}{ }^{C} \\
\left({ }^{\circ} \mathrm{C}\right)\end{array}$ & $\begin{array}{c}\Delta H \\
\left(\mathrm{~J} \cdot \mathrm{g}^{-1}\right)\end{array}$ & $\begin{array}{c}T_{g} \\
\left({ }^{\circ} \mathrm{C}\right)\end{array}$ & $\begin{array}{c}T_{m} \\
\left({ }^{\circ} \mathrm{C}\right)\end{array}$ & $\begin{array}{c}\Delta H \\
\left(\mathrm{~J} \cdot \mathrm{g}^{-1}\right)\end{array}$ \\
\hline $\mathrm{PGI}_{20}$ & 370 & 420,464 & 2 & - & 54 & 83 & - & - & - & 49 & 51 \\
\hline \multicolumn{12}{|l|}{ Poly[GI $\left.{ }_{8}-c o-(\mathrm{TGI})_{12}\right]$} \\
\hline Poly[GI-co-(GIBAET $\left.)_{12}\right]$ & 235 & 400,460 & 3 & - & - & - & - & - & - & - & - \\
\hline Poly $\left[\mathrm{Gl}_{8}-\mathrm{CO}-\left(\mathrm{GINH}_{2}\right)_{12}\right]$ & 190 & 270 & 20 & - & - & - & - & - & - & - & - \\
\hline \multicolumn{12}{|l|}{ Poly $\left[\mathrm{GI}_{20}-\right.$ graft-(AA) $\left.{ }_{z}\right]$} \\
\hline Poly $\left.\left[\mathrm{Gl}_{20} \text {-graft-(BLG) }\right)_{5}\right]$ & 370 & 310,400 & 13 & 21 & - & - & 113 & 0.4 & 21 & - & - \\
\hline Poly $\left.\left[\mathrm{Gl}_{20} \text {-graft-(BLG) }\right)_{12}\right]$ & 255 & 310 & 14 & 21 & - & - & 120 & 0.6 & 21 & - & - \\
\hline$P B L G_{50}$ & 280 & 290 & 16 & 21 & - & - & 118 & 9 & 21 & - & - \\
\hline Poly[GI ${ }_{20}$-graft-(ZLL) $\left.)_{5}\right]$ & 245 & 410 & 2 & - & - & - & - & - & - & - & - \\
\hline Poly[GI ${ }_{20}$-graft-(ZLL) $\left.)_{12}\right]$ & 230 & 410 & 10 & - & - & - & - & - & - & - & - \\
\hline $\mathrm{PZLL}_{50}$ & 260 & 330 & 9 & 21 & - & - & - & - & 21 & - & - \\
\hline Poly $\left[\mathrm{Gl}_{20} \text {-graft-(LGA) }\right)_{5}$ & 235 & 360 & 36 & - & - & - & - & - & - & - & - \\
\hline Poly $\left[\mathrm{GI}_{20}-\right.$ graft-$\left.(\mathrm{LGA})_{12}\right]$ & 190 & 350 & 30 & - & - & - & - & - & - & - & - \\
\hline Poly $\left.\left[G_{20} \text {-graft-(LL) }\right)_{5}\right]$ & 233 & 340,430 & 16 & - & - & - & - & - & - & - & - \\
\hline Poly[Gl $\mathrm{Gl}_{20}$-graft-(LL) $\left.{ }_{12}\right]$ & 242 & 330 & 2 & - & - & - & - & - & - & - & . \\
\hline
\end{tabular}

${ }^{2}$ Onset temperature for $5 \%$ of weight loss $\left({ }^{\circ} T_{d}\right)$, maximum rate decomposition temperature $\left({ }^{\max } T_{d}\right)$ and remaining weight $\left(R_{w}\right)$ after heating at $600{ }^{\circ} \mathrm{C}$. Only ${ }^{\max } T_{d}$ main peaks are indicated (see Figures S4 and S5 for a graphical description.

${ }^{\mathrm{b}}$ Glass transition temperature $\left(T_{g}\right)$ and melting temperature and enthalpy $\left(T_{m}\right.$ and $\left.\Delta H_{m}\right)$ measured from pristine samples (first heating) and from molten samples (second heating).

${ }^{c} T_{L C}$ is a solid state phase transition temperature caused by a conformational change taking place in the PBLG segment.

characteristics appears at $118^{\circ} \mathrm{C}$ for PBLG due to an irreversible transition involving a rearrangement from the $7 / 2$ to the $18 / 5 \alpha$-helical conformation [50]. This interpretation is reasonable for explaining the peak displayed by the BLG-grafted copolymers and is supported by the fact that it decreases in both temperature and enthalpy when the length of the BLG-grafts decreases from 12 to 5 . The glass transition was only observed for the BLG-grafted copolymers and for $\mathrm{PZLL}_{50}$ at a common value of $21^{\circ} \mathrm{C}$, which is amazingly the same value displayed by $\mathrm{PBLG}_{50}$ (enlarged versions of the copolymer thermograms are provided in the SI to make more clearly visible the slope changes characteristic of these transitions). No other transition was observed for any copolymer either at cooling or at heating from the melt (see Figure S6 in the SI file). 


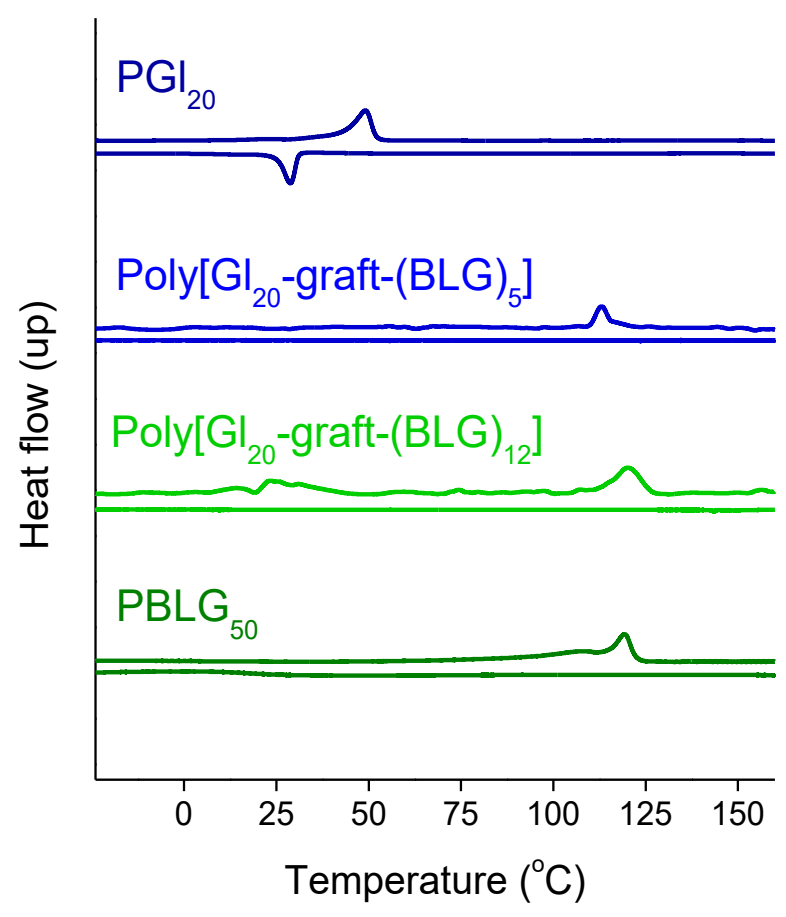

Figure 3. DSC registered at the first heating and subsequent cooling from poly[ $\mathrm{Gl}_{20}$-graft$\left.(B L G)_{z}\right]$ copolymers.

To support the interpretation made for DSC, poly[G| ${ }_{20}$-graft-(AA) $]$ copolymers bearing the amino acids protected were analyzed by FTIR, and their spectra compared with those registered from their respective homopolypeptides PBLG and PZLL. The spectral region containing both Amide I and Amide II bands characteristic of polypeptides, which are commonly used for detecting the presence of $\alpha$-helix and $\beta$ sheet structures, is depicted in Figure 4 for both BLG- and ZLL-grafted copolymers. It is observed that whereas the helical conformation is that exclusively adopted by the two homopolypeptides (the absorption attributable to the $\beta$-sheet is very weak), the two structures become clearly visible in the copolymers with side chains containing 12 amino acids in average. The relative importance of the two forms reversed in copolymers with short side chains (with 5 amino acids in average) so that the $\beta$-sheet structure becomes preponderant in poly $\left.\left[\mathrm{Gl}_{20} \text {-graft-(BLG)}\right)_{5}\right]$ and almost unique in poly $\left[\mathrm{Gl}_{20} \text {-graft-(ZLL) }\right)_{5}$. It can be concluded therefore that the helical conformation is 
favored by longer amino acid sequences and also that its relative importance is higher in the ZLL-grafted copolymers. These observations are fully consistent with the wellknown general structural behavior of polypeptides [51] and in good agreement with what has been reported for other copolymers containing segments made of BLG or ZLL units [52].

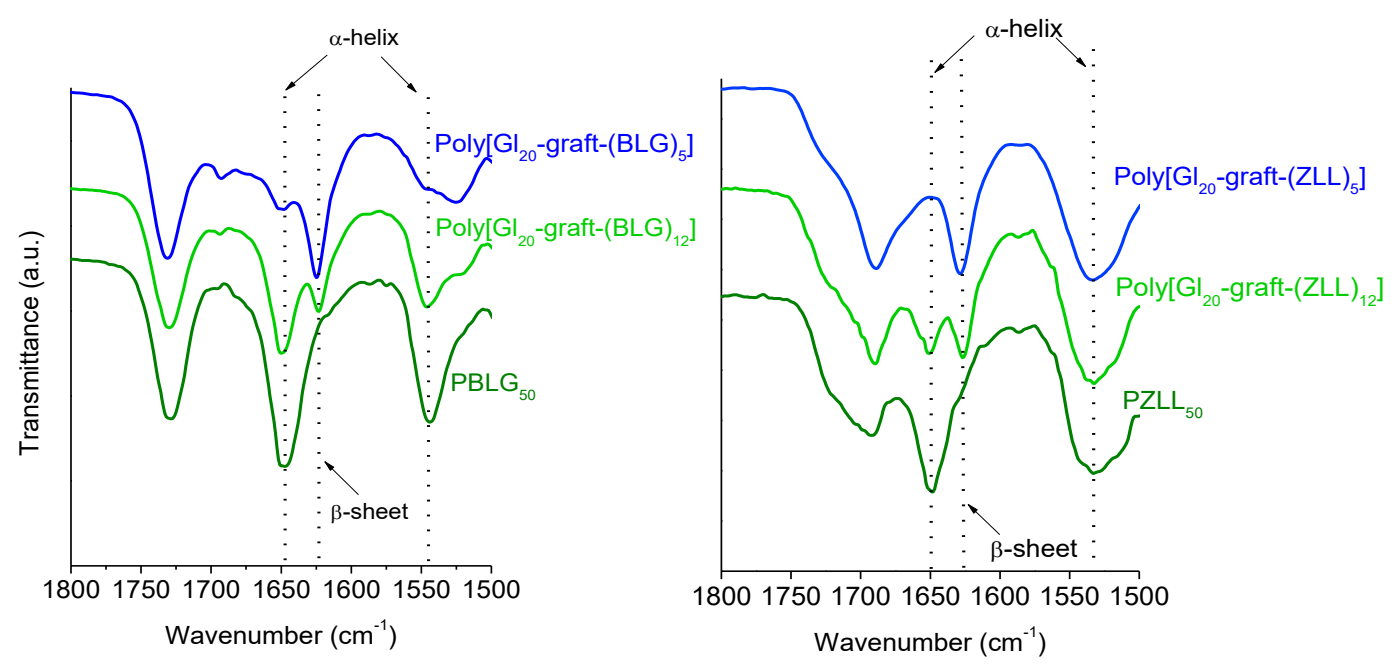

Figure 4. Amide I and II region of the FTIR spectra registered from poly $\left[\mathrm{Gl}_{20}-\right.$ graft- $\left.(\mathrm{pAA})_{z}\right]$ copolymers and PBLG and PZLL homopolypeptides.

\subsection{Supramolecular structure}

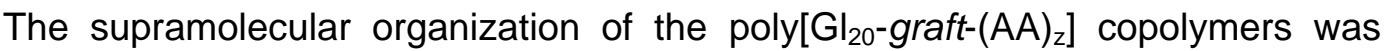
examined by $\mathrm{X}$-ray diffraction (XRD) at variable temperature using synchrotron radiation. The WAXS and SAXS results obtained in the analysis of poly[G| ${ }_{20}$-graft$(B L G)_{12}$ are shown in Figure 5. At low temperature the discrete scattering produced by the copolymer was poor and uncertainly interpreted. The profile registered at $10{ }^{\circ} \mathrm{C}$ in the WAXS region displayed broad peaks at approximately 1.5 and $0.5 \mathrm{~nm}$ whereas in the SAXS region a shoulder at $5.4 \mathrm{~nm}$ was the only signal observed. Since the FTIR spectra revealed the presence of both $\alpha$ - and $\beta$-sheet forms in this copolymer at room temperature, such signals should be associated to supramolecular structures defectively formed by the copolymer with the polypeptide branches arranged in one or 
other of these two conformations. Conversely, the scattering produced at $200{ }^{\circ} \mathrm{C}$ in the medium-angle region displayed meaningful discrete information consisting of a set of
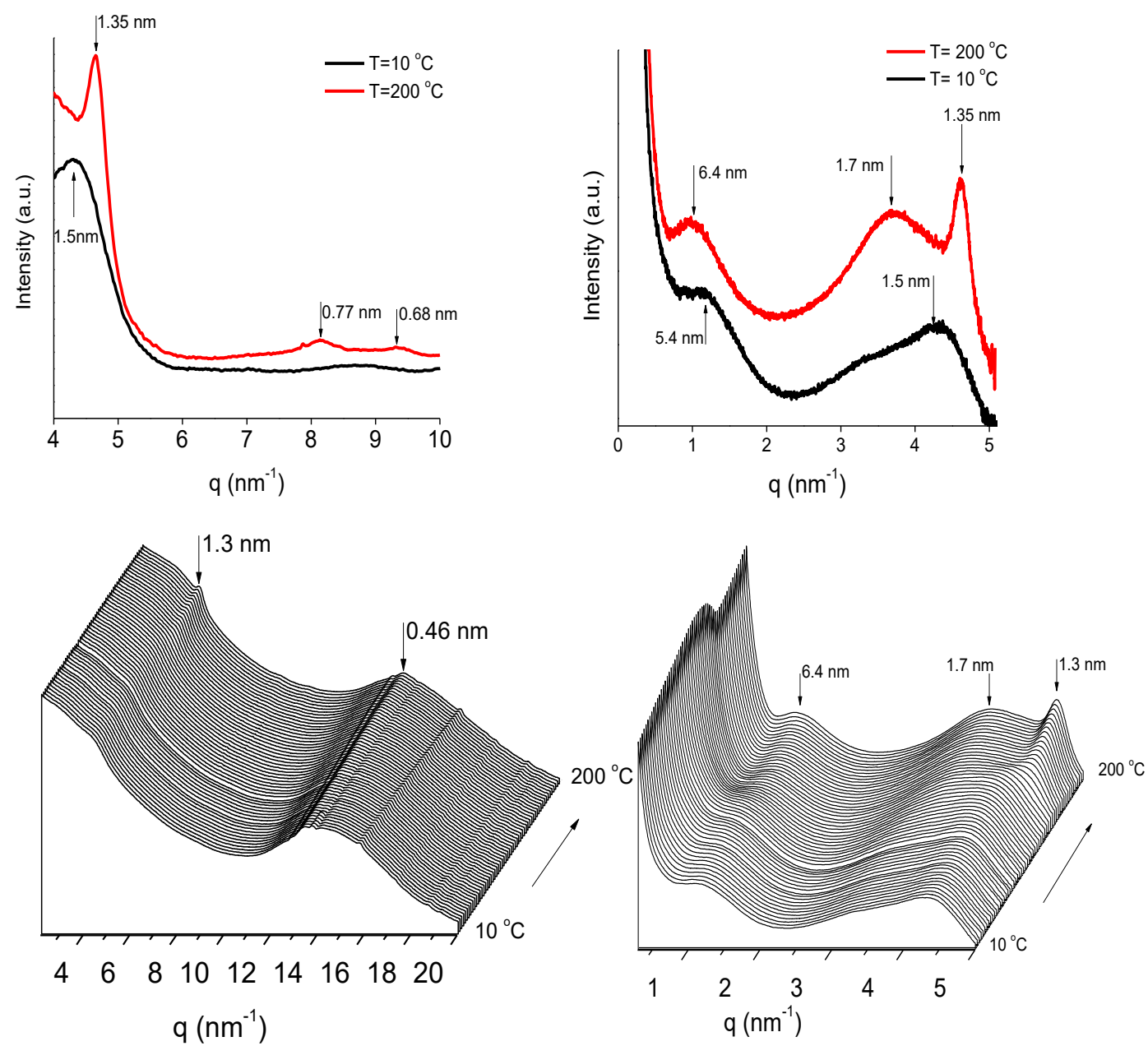

Figure 5. WAXS (left) and SAXS (right) profiles registered from poly[ $\left[\mathrm{Gl}_{20}\right.$-graft-(BLG $\left.\left.\mathrm{B}_{12}\right)\right]$ at different temperatures. The profiles registered at $10{ }^{\circ} \mathrm{C}$ and $200{ }^{\circ} \mathrm{C}$ are compared in the top plots. The evolution of the profiles recorded at real time vs heating over the $10-200{ }^{\circ} \mathrm{C}$ range is displayed in the bottom figures.

Bragg reflections at $1.35,0.77$ and $0.68 \mathrm{~nm}$ which fit well into a $1: 3^{1 / 2}: 2$ ratio. According to literature [53] and to our own previous studies on block polyester-polypeptide copolymers as well [31], such diffraction pattern must be interpreted as arising from a columnar-hexagonal packing of $(B L G)_{12} \alpha$-helices of approximately $1.6 \mathrm{~nm}$ diameter. On the other hand, the scattering observed in the SAXS region at $10^{\circ} \mathrm{C}$ was essentially 
retained after heating at $200{ }^{\circ} \mathrm{C}$ but with intensity increased and slightly displaced to lower $q$ values.

The XRD analysis of the poly[G| ${ }_{20}$-graft-(ZLL) $\left.{ }_{12}\right]$ copolymer provided profiles as those depicted in Figure 6. According to FTIR, the relative importance of the $\beta$-form to the $\alpha$-helical form is higher in ZLL-grafted than in BLG-grafted copolymers and it is corroborated by XRD results. In fact, the WAXS profiles obtained for poly[ $\left[\mathrm{Gl}_{20}\right.$-graft$\left.(Z L L)_{12}\right]$ at any temperature do not display any significant discrete scattering except the $0.46 \mathrm{~nm}$ broad peak which can be assumed to arise, at least in part, from the average interchain distance present in the $\beta$-sheet structure. In the SAXS region, two peaks at 2.4 and $4.8 \mathrm{~nm}$ are observed at low temperature whereas only the former remains after
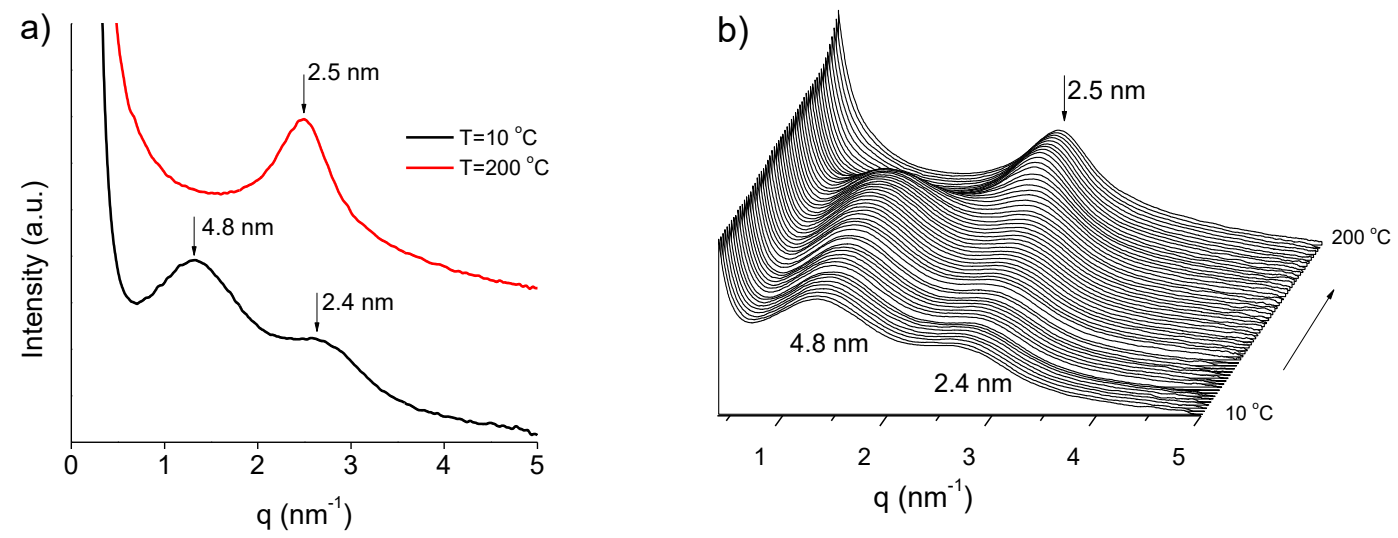

Figure 6. XRD profiles registered from poly $\left[\mathrm{Gl}_{20}-\right.$ graft- $\left.\left(\mathrm{ZLL}_{12}\right)\right]$ at different temperatures. The profiles registered in the SAXS region $\left(q=0.5-5 \mathrm{~nm}^{-1}\right)$ at $10{ }^{\circ} \mathrm{C}$ and $200{ }^{\circ} \mathrm{C}$ are compared in a). The evolution followed by the profiles when heated from 10 to $200^{\circ} \mathrm{C}$ is displayed in b).

heating at $200{ }^{\circ} \mathrm{C}$ although slightly displaced up to $2.5 \mathrm{~nm}$. The $2.3-2.4 \mathrm{~nm}$ peak could be attributed to the lamellar thickness made of ZLL-segments crystallized in $\beta$-sheet conformation. It seems therefore that at difference with poly[ $\left[\mathrm{Gl}_{20}\right.$-graft-(BLG) $\left.{ }_{12}\right]$ and also with data reported by Lecommandoux et al. [52] for block copolymers made of styrene and ZLL, the $\alpha$-helices adopted by PZLL in poly[G| ${ }_{20}$-graft-(ZLL) $\left.{ }_{12}\right]$ are unable to form columnar liquid-crystal structures. 


\subsection{Self-assembling of poly $\left[\mathrm{Gl}_{20}-\right.$ graft-(AA) $]$ copolymers in aqueous medium}

As it could be reasonably expected, the poly $\left.\left[\mathrm{Gl}_{20^{-}} \text {graft-(AA) }\right)_{z}\right]$ copolymers grafted with protected amino acids are non-water soluble due to the high hydrophobic character of the aromatic groups used for protection. The situation is just the opposite when unprotected copolymers are concerned. The presence of multiple carboxylic or amino groups makes the copolymers to be water-soluble in greater or lesser extension depending on the length of the branches. In relation to the potential applications envisaged for these copolymers, their behavior in aqueous environments and in particular their capacity to generate organized aggregates, has been examined. Data relative to critical micelle concentration $(\mathrm{cmc})$, particle diameter and dispersity ( $D$ and $P D I)$ and zeta potential $(\zeta)$ of the aggregates spontaneously formed when poly[ $\left[\mathrm{Gl}_{20^{-}}\right.$ graft- $\left.(A A)_{z}\right]$ copolymers were placed in water are collected in Table 3.

Table 3. Characterization of NPs made of poly $\left[\mathrm{Gl}_{20}-\right.$ graft- $\left.(\mathrm{AA})_{z}\right]$ copolymers and polyplexes.

\begin{tabular}{|c|c|c|c|c|c|}
\hline Polymer & $\begin{array}{c}c m c \\
\left(\mathrm{mg} \cdot \mathrm{mL}^{-1}\right)\end{array}$ & $\begin{array}{c}\text { Conc } \\
\left(\mathrm{mg} \cdot \mathrm{mL}^{-1}\right)\end{array}$ & $D(\mathrm{~nm})$ & $D$ & $(\mathrm{mV})$ \\
\hline 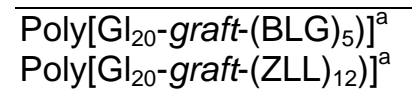 & - & $\begin{array}{l}1.5 \\
1.5\end{array}$ & $\begin{array}{l}165 \\
130\end{array}$ & $\begin{array}{l}0.30 \\
0.29\end{array}$ & $\begin{array}{l}-47 \\
-24\end{array}$ \\
\hline $\begin{array}{l}\left.\text { Poly }\left[\mathrm{GL}_{20} \text {-graft- }(\mathrm{LGA})_{5}\right)\right]^{\mathrm{a}} \\
\text { Poly }\left[\mathrm{GL}_{20} \text {-graft- }\left(\mathrm{LL}_{12}\right)\right]^{\mathrm{a}}\end{array}$ & $\begin{array}{l}1.38 \\
0.50\end{array}$ & $\begin{array}{l}1.0 \\
1.0\end{array}$ & $\begin{array}{l}50-300 \\
80-400\end{array}$ & $\begin{array}{l}0.36 \\
0.31\end{array}$ & $\begin{array}{l}-12 \\
27\end{array}$ \\
\hline $\begin{array}{l}\left.\text { Poly }\left[\mathrm{GI}_{20} \text {-graft- }(\mathrm{LGA})_{5}\right)\right]^{\mathrm{b}} \\
\text { Poly }\left[\mathrm{Gl}_{20} \text {-graft-(LGA }\left(\mathrm{LA}_{12}\right)\right]^{\mathrm{b}}\end{array}$ & $\begin{array}{l}1.38 \\
0.50\end{array}$ & $\begin{array}{l}1.0 \\
1.0\end{array}$ & $\begin{array}{l}25 / 106 \\
20 / 140\end{array}$ & $\begin{array}{l}0.40 \\
0.44\end{array}$ & $\begin{array}{l}-11 \\
-36\end{array}$ \\
\hline $\begin{array}{l}\text { Poly }\left[\mathrm{GI}_{20}-\text { graft- }(\mathrm{LL})_{5}\right]^{\mathrm{b}} \\
\text { Poly[}\left[\mathrm{Gl}_{20} \text {-graft- }\left(\mathrm{LL}_{12}\right)\right]^{\mathrm{b}}\end{array}$ & $\begin{array}{l}0.44 \\
0.10\end{array}$ & $\begin{array}{l}0.5 \\
2.0\end{array}$ & $\begin{array}{c}140 \\
20 / 150\end{array}$ & $\begin{array}{l}0.40 \\
0.56\end{array}$ & $\begin{array}{l}46 \\
51\end{array}$ \\
\hline $\begin{array}{l}\left.\text { Poly }\left[G_{20} \text {-graft }(\mathrm{LGA})_{5}\right)\right]+ \\
+ \text { Poly }\left[\mathrm{Gl}_{20} \text {-graft }(\mathrm{LL})_{5}\right]^{\mathrm{C}}\end{array}$ & - & $5: 1.5$ & 500 & 0.12 & 7.0 \\
\hline
\end{tabular}

The $\mathrm{cmc}$ of the water-soluble copolymers was measured by DLS and the plots used for determination are shown in Figure S7 of the SI file. The $\mathrm{cmc}$ was found to decrease as the length of the grafted polypeptide branch increased, which is contrary to expectations since water solubility of these copolymers must increase for larger 
contents in free amino acids. It is a pending issue of this work that needs further specific attention to be explained.

The nanoprecipitation method from DMF solutions at $1.5 \mathrm{mg} \cdot \mathrm{mL}^{-1}$ copolymer concentration was applied to prepare nanoparticles from poly[G| $\mathrm{G}_{20}$-graft-(BLG)$\left.)_{5}\right]$ and poly $\left[\mathrm{Gl}_{20}\right.$-graft-(ZLL) $\left.{ }_{12}\right]$ copolymers in which the $\mathrm{COOH}$ and $\mathrm{NH}_{2}$ groups are protected. As it is illustrated in Figure 7, almost monomodal distributions of entities with average diameters of 165 and $130 \mathrm{~nm}$, respectively, and negative zeta-potential were obtained. TEM observations of these aggregates showed more or less rounded particles that are frequently collapsed most likely due to their deposition on the supporting film used for observation.

a)
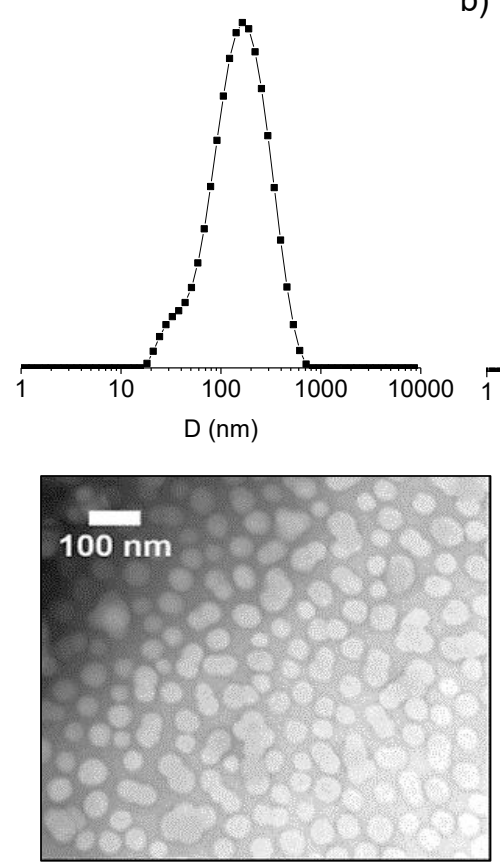

b)
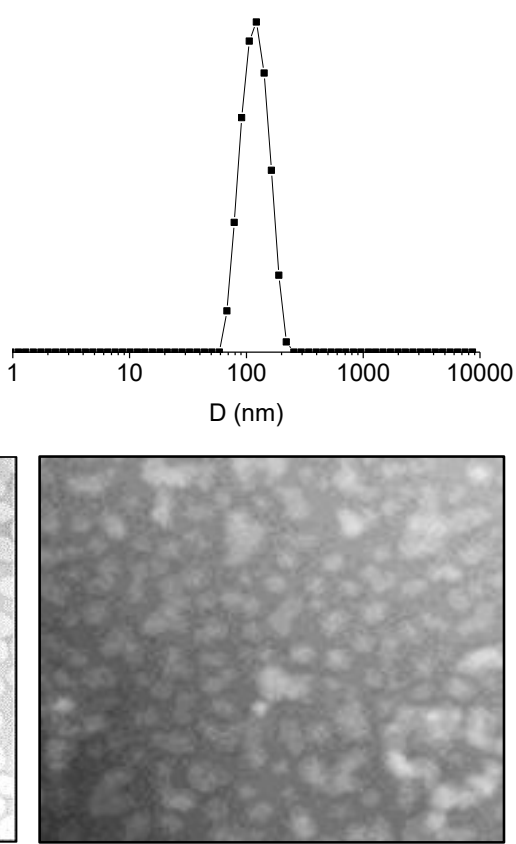

Figure 7. Size distribution profiles and TEM images of nanoparticles made of: a) poly[G| $\mathrm{Gl}_{20}$-graft$\left.(\mathrm{BLG})_{5}\right]$ and b) poly[GI ${ }_{20}$-graft-(ZLL) $\left.)_{12}\right]$.

The application of the nanoprecipitation method to copolymers poly[ $\mathrm{Gl}_{20}$-graft$\left.(\mathrm{LGA})_{5}\right]$ and poly[GI ${ }_{20}$-graft-(LL) $\left.{ }_{12}\right]$ with the amino acids constitutive of the polypeptide side chains in the free form produced nanoparticles displaying a bimodal distribution of sizes with respective average diameters of $50 / 80 \mathrm{~nm}$ and $300 / 400 \mathrm{~nm}$. The zeta- 
potential sign of the particles made of lysine-grafted copolymers was inverted upon deprotection, as it should be expected from the cationic charge that is created on the lysine residues. DLS data and TEM micrographs recorded for these copolymers illustrating vividly the bimodal composition are included in Figure S8 of the SI file. To investigate the copolymer aggregation in water without mediation of organic solvents, poly $\left[\mathrm{Gl}_{20} \text {-graft-(LGA)}\right)_{5}$ and poly[Gl $\mathrm{Go}_{20}$ graft-(LL) $\left.)_{5}\right]$ were dissolved in water at concentrations above their respective $c m c$ and their solutions were examined by DLS to measure size and zeta potential of the aggregates as a function of concentration. Size distribution traces and representative TEM images of these preparations are shown in Figure 8 and average diameters, dispersities and zeta-potentials are compared in Table 3. To explore the stability of these NPs with time, aliquots were withdrawn every $24 \mathrm{~h}$ for one week, and the changes taking place in size were assessed by DLS.

a)

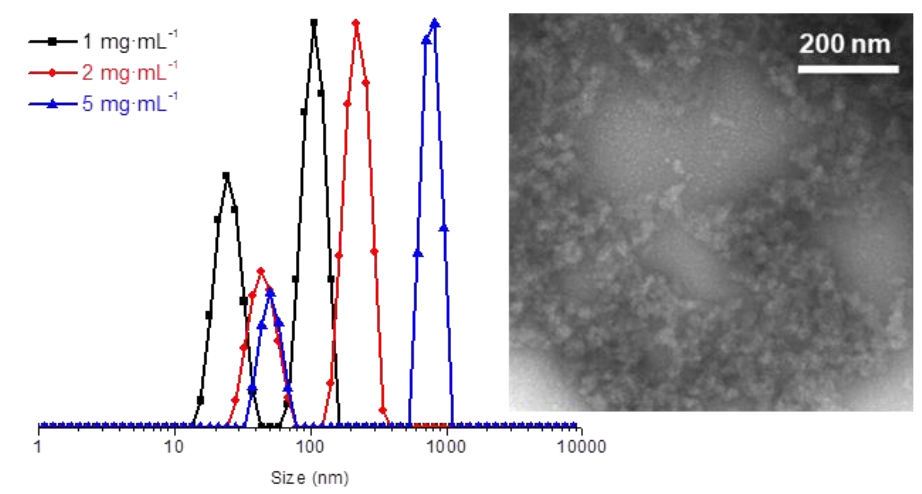

b)

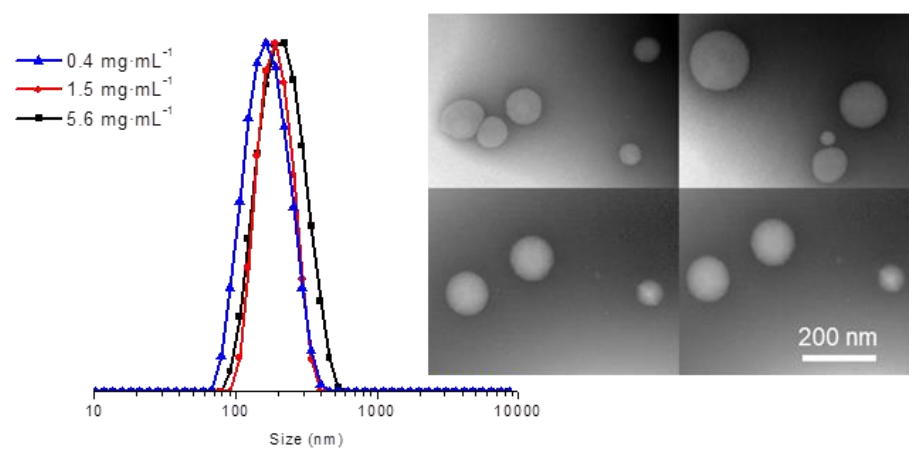

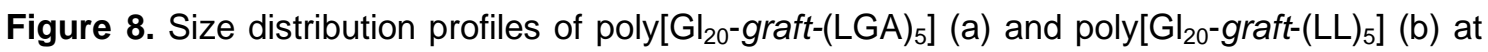
different copolymer concentrations. On the right TEM images of their respective micelles made from the lowest concentration solutions $\left(1 \mathrm{mg} \cdot \mathrm{mL}^{-1}\right.$ and $0.4 \mathrm{mg} \cdot \mathrm{mL}^{-1}$, respectively). 
Both types of particles were found to be fairly stable with sizes remaining essentially constant over the whole period of experimentation. The DLS profiles obtained for the different scheduled incubation times and the plot of nanoparticles average diameters as a function of time are shown in the SI file as Figure S9.

\subsection{Ionic coupling of deprotected copolymers: drug conjugates and polyplexes}

\subsubsection{DOX loading and delivery}

DOX is an amphiphilic compound that may be positively charged due to the protonable amino group contained in its sugar moiety. DOX is today one of the most used drugs for cancer therapy and frequently taken as model to assess the potential of novel drug delivery systems that are designed with such purpose. To evaluate the capacity of poly[Gl $\mathrm{G}_{20}$-graft-(LGA) $\left.{ }_{12}\right]$ to load DOX, the NPs formed from an aqueous solution of the copolymer $\left(1.2 \mathrm{mg} \cdot \mathrm{mL}^{-1}\right)$ to which a DOX solution was simultaneously added were examined by DLS and compared with those prepared from the copolymer alone. Results are graphically depicted in Figure 9 indicating that upon conjugation, the bimodal distribution of sizes became monomodal and increased in diameter from 20/150 $\mathrm{nm}$ up to $260 \mathrm{~nm}$. The zeta-potential changed also to become less negative (from $-34 \mathrm{mV}$ to $-22 \mathrm{mV}$ ). These results are according with the coupling mechanism that is expected to operate for the loading of positively charged DOX onto the carboxylate-free copolymer. Drug loading efficiency (DLE) and drug loading content (DLC) were measured for different copolymer/drug proportions used for preparing the loaded NPs and their values are represented in Figure 10. Both indexes increased steadily with the relative amount of DOX up to DOX:copolymer ratio of 0.6 . At this point, $63 \%$ and $38 \%$, were the values attained by DLE and DLC, respectively. For higher amounts of DOX, a significant decreasing was observed for DLE whereas DLC slightly changed. It can be inferred that ionic coupling attained its maximum at the 0.6 ratio. Although not all the negative charges present in poly[ $\mathrm{Gl}_{20}$-graft- $\left.(\mathrm{LGA})_{12}\right]$ have 
been neutralized at such ratio, it is reasonable to assume that a good number of carboxylate groups present in the copolymer are not accessible to DOX. This is in agreement with the fact the zeta-potential of the DOX loaded NPs is still negative.

a)

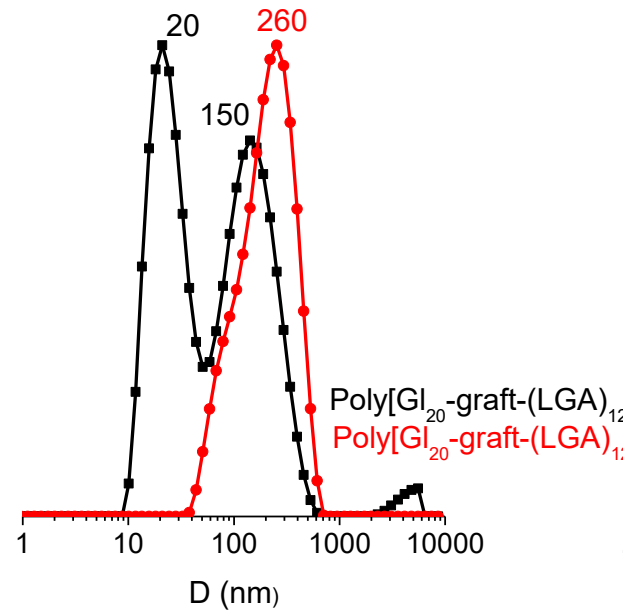

b)

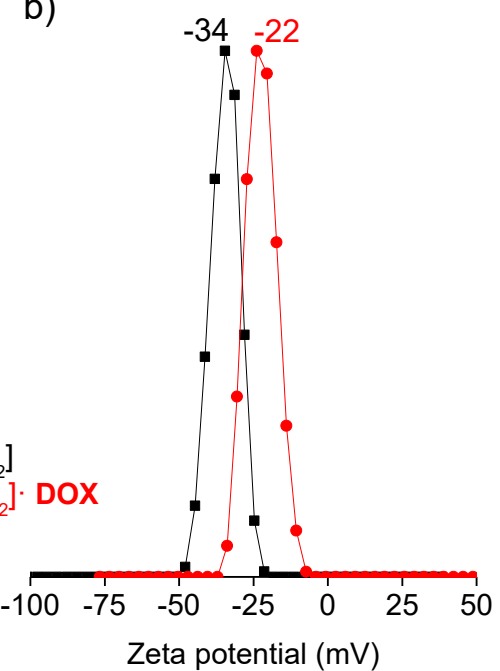

Figure 9. DLS (a) and zeta potential (b) profiles of poly[G| $\left.\right|_{20}$-graft-(LGA) $\left.{ }_{12}\right] \cdot$ nanoparticles unloaded and loaded with DOX.

a)

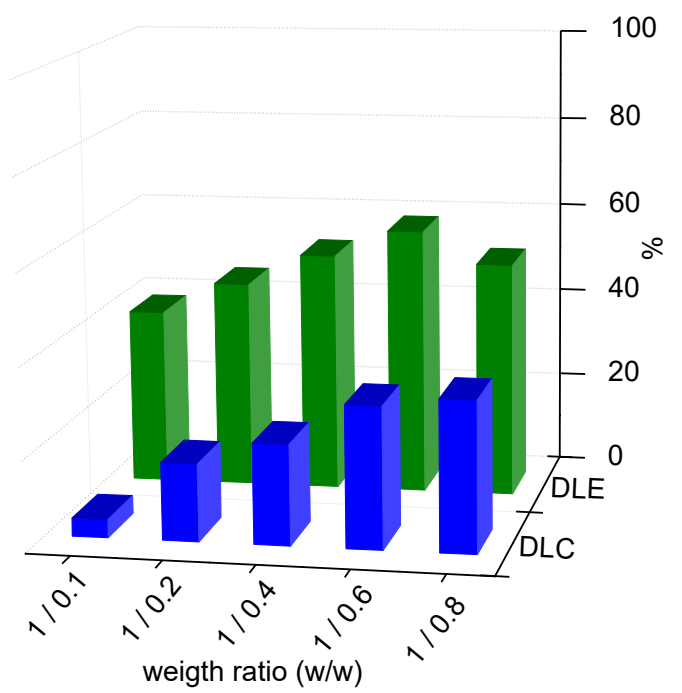

b)

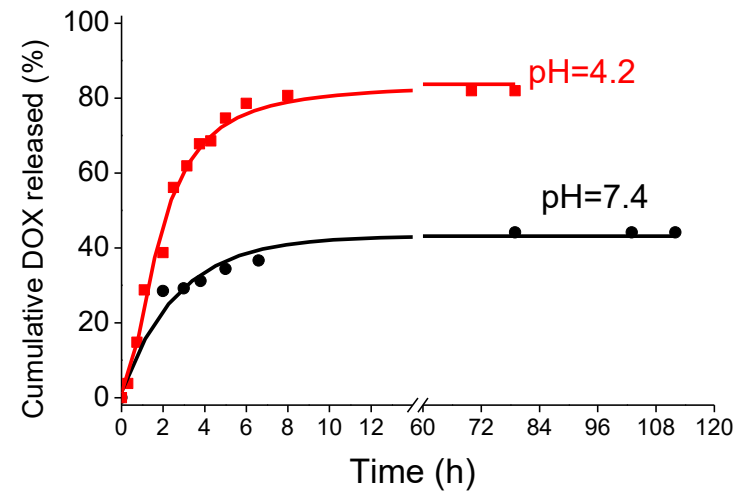

Figure 10. a) DLE and DLC for different poly[G| ${ }_{20}$-graft-(LGA) $\left.{ }_{12}\right]$ :DOX ratios. b) In vitro release profiles of poly[G| $\mathrm{G}_{20}$-graft-(LGA) $\left.{ }_{12}\right] \cdot \mathrm{DOX}$ nanoparticles at $\mathrm{pH} 7.4$ and 4.2.

The in vitro release profiles of poly[G| $\mathrm{G}_{20}$-graft-(LGA) $\left.)_{12}\right] \cdot \mathrm{DOX} N \mathrm{NS}$ that were loaded at a DOX:copolymer feed ratio of 0.6 are shown in Figure 10 for two different $\mathrm{pHs}$ (4.2 
and 7.4). These $\mathrm{pH}$ values were selected because tumor extracellular $\mathrm{pH}$ values range from $\mathrm{pH} 6.5$ to $\mathrm{pH} 7.2$, whereas the $\mathrm{pH}$ within cancerous cells may be between $\mathrm{pH} 4.0$ and 5.0 depending on location [54]. In both cases, DOX delivery happened within the first eight hours of incubation but the total amount of released drug and releasing rate were noticeably higher in the acid medium. These results are consistent with the ionic coupling that is assumed to occur between DOX and the copolymer. At pH 4.2 a significant reduction in the ionization degree of LGA moieties must take place with the subsequent disruption of the electrostatic interactions.

It is known that macrolactones do not degrade either under hydrolytic or enzymatic environment, which is ascribed to their high crystallinity and hydrophobicity [42]. It was expected therefore that electrostatic dissociation of the DOX.Poly[GI ${ }_{20}{ }^{-}$ graft-LGA ${ }_{12}$ ] complex by the medium is the mechanism responsible for the release of DOX. To ascertain a blank copolymer sample (without DOX) was incubated under the same conditions used for releasing $\left(8 \mathrm{~h}, 37^{\circ} \mathrm{C}, \mathrm{pH} 4.2\right)$. After incubation, no significant detectable changes in composition were detected by NMR (Figure S12 in SI). The relative intensity of the characteristic signals of the polypeptide ( $\alpha$ protons) and poly(globalide) (a protons) remained unaltered and not new signals arising associated to the presence of carboxylic or hydroxyl end groups appeared. It can be ascertained therefore that DOX is delivered to the aqueous medium as a consequence of complex dissociation and that degradation of the polyester is negligible under the used incubation conditions.

\subsubsection{Polyplex formation and DNA complexation}

At the last stage of this work and as a preliminary assessment of the capability of the cationic poly[Gl $\mathrm{Gl}_{20}$-graft- $\left.(\mathrm{LL})_{\mathrm{z}}\right]$ copolymers to condensate DNA, aggregates formed from mixtures of LGA- and LL-grafted copolymers were investigated. Since they are oppositely charged it is expected that they become spontaneously assembled in definite objects stabilized by electrostatic interactions. Water solutions of poly[ $\left[\mathrm{Gl}_{20^{-}}\right.$ 
graft-(LGA $\left.)_{5}\right]$ and poly[ $\left[\mathrm{Gl}_{20} \text {-graft-(LL) }\right)_{5}$ were mixed at room temperature by adding dropwise one to the other, and the resulting solution was examined by DLS and TEM. Results obtained when the Lys-grafted copolymer solution $\left(1.5 \mathrm{~g} \cdot \mathrm{mL}^{-1}\right)$ was added dropwise to a similar volume of LGA-grafted copolymer solution (5 $\mathrm{mg} \cdot \mathrm{mL}^{-1}$ ) are graphically shown in Figure 11 and numerically collected in Table 3. As it is clearly illustrated in Figure 11, a monomodal population of polyplex particles with an average diameter around $500 \mathrm{~nm}$ were formed, which is a size about four-five times larger than those displayed by the particles detected in each separate solution. The zeta-potential measured for these particles was intermediate between the values displayed by the single copolymer particles, and TEM observations showed that they are essentially round. The addition order followed for mixing was not critical since similar results were obtained when the LGA-grafted copolymer was added to the LL-grafted one with the only difference being that a somewhat larger particle size resulted in this case (Figure S10 of the SI file). Conversely, solutions concentrations seem to be critical for the formation of the polyplex since no particles were detected when the same concentration was used for the two mixing solutions but a precipitate was obtained instead.

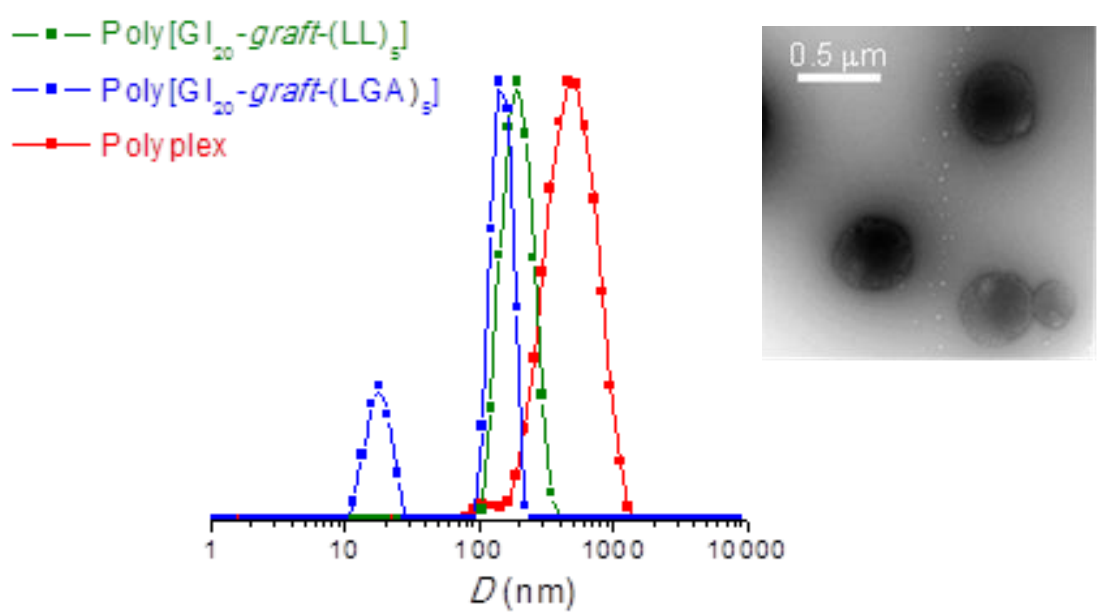

Figure 11. DLS profile recorded from the polyplex generated by mixing equal amounts of the LGA-grafted the LL-grafted copolymer solutions at a concentration of $5 \mathrm{mg} \cdot \mathrm{mL}^{-1}$. Profiles obtained from the separate solutions are included for comparison. A TEM representative picture of the polyplex particles is shown in the inserted image. 
The capability of the anionic poly[G| ${ }_{12}-$ graft-(LL) $\left.)_{5}\right]$ copolymer for condensing DNA was assessed by examining the formation of polyplexes with salmon testes DNA ( $s t D N A, 2,000 \mathrm{bp}$ ). For this, aqueous polymer solutions of copolymer and stDNA were mixed at different proportions expressed as nitrogen/phosphorous ratio (N/P). N and $\mathrm{P}$ values were determined by considering that the poly[Gl $\mathrm{G}_{12}$-graft-(LL) $\left.{ }_{5}\right]$ mass per cationic charge (one per amino $\mathrm{N}$ atom) is $225 \mathrm{~g} \cdot \mathrm{mol}^{-1}$ and the DNA mass per anionic charge (one per $\mathrm{P}$ atom) is $\sim 325 \mathrm{~g} \mathrm{~mol}^{-1}$. The copolymer/DNA polyplexes were formed at room temperature upon dropwise addition of the copolymer solution to the DNA one followed by incubation of the mixture for $20 \mathrm{~min}$ at room temperature. A wide N/P range going from 5 to 140 was tested and the mixed solutions were analyzed by DLS. Monomodal profiles registered from these mixtures are shown in Figure S11 of the SI file.
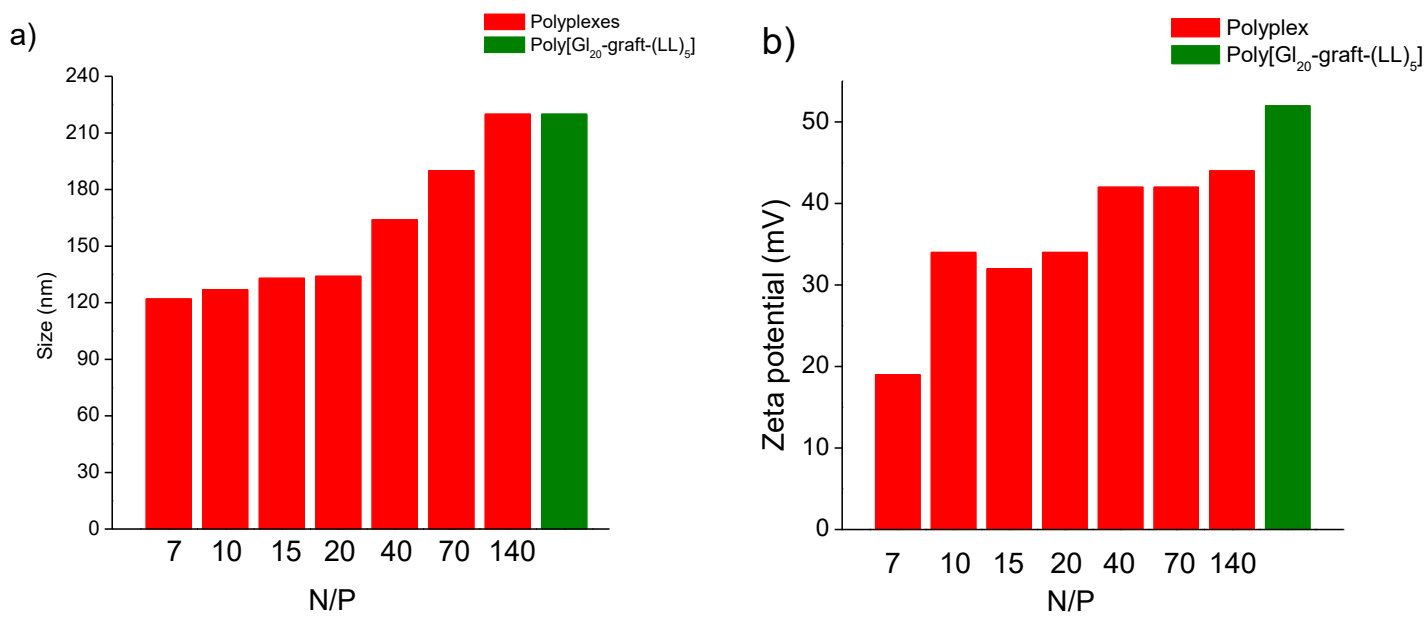

Figure 12. Diameter (a) and zeta potential (b) of polyplexes nano-objects formed from poly[Gl ${ }_{12^{-}}$ graft-(LL) $\left.)_{5}\right]$ and stDNA at different N/P ratios.

As it is represented in the bar plot of Figure 12, the stable nanoaggregates formed by ionic coupling of poly[Gl $\mathrm{G}_{12}$ graft-(LL) $\left.)_{5}\right]$ with stDNA showed average diameters steadily decreasing from $220 \mathrm{~nm}$, which is the size of the particles formed from the single copolymer, to $120 \mathrm{~nm}$ for a N/P ratio of 7 . The zeta-potential showed a similar trend with a decrease from around $50 \mathrm{mV}$ for the poly[Gl ${ }_{12}$-graft-(LL) $\left.)_{5}\right] \mathrm{NPs}$ down to less than $20 \mathrm{mV}$. N/P ratios lower than 7 produced precipitates presumably consisting 
of unspecific NP aggregates caused by DNA interlocking. Since the length of the stDNA used in this study is near to $1000 \mathrm{~nm}$, the drastic reductions observed in diameter and Z-potential of NPs are taken as clear evidences for the DNA condensating capacity of poly[Gl ${ }_{12}$-graft-(LL) $)_{5}$ copolymer [55].

\subsection{Conclusions}

A polyglobalide (PGI) made of 20 monomeric units in average was obtained by enzymatic ROP using Novozyme 435. This PGI was made to react with 2-(Bocamino)ethanethiol to afford a PGI copolymer containing about $60 \%$ of globalide units bearing a pendant amino group. The aminated polyglobalide was effective in initiating conveniently protected L-Glu and L-Lys NCA ROP to produce poly[G| $\mathrm{G}_{20}$-graft-(AA) $]$ copolymers with side chains made of either 5 or 12 units of each one of these two amino acids. These neutral copolymers could be readily deprotected to render polycharged anionic and cationic copolymers respectively. Both protected and deprotected poly[ $\left[\mathrm{Gl}_{20}\right.$-graft- $\left.(\mathrm{AA})_{\mathrm{z}}\right]$ copolymers were amorphous but the poly(amino acid) side chains were arranged in either $\alpha$-helix of $\beta$-sheet regular conformation. Powder XRD of poly $\left[\mathrm{Gl}_{20}\right.$-graft- $\left.(\mathrm{AA})_{\mathrm{z}}\right]$ showed discrete scattering in the 2.5-6.5 nm range of spacings indicating the presence of organized supramolecular structures in these copolymers when they are in the solid state. In aqueous medium all the copolymers were arranged in nano-objects with a size and surface charge depending on their constitution. The capacity of anionic poly[G| $\mathrm{G}_{20}$-graft-(LGA) $)_{5}$ and cationic poly $\left[\mathrm{Gl}_{20} \text {-graft-(LL) }\right)_{5}$ nanoparticles for loading and releasing DOX and condensing DNA, respectively, was assessed in vitro essays. DLE and DLC values found for DOX were around $60 \%$ and $40 \%$, and DNA was efficiently packed in the NPs over a wide range of cationic/anionic charges ratio. 


\section{Acknowledgements}

Financial support for this research was afforded by MINECO with grant MAT2016-77345-CO3-01. E. Tinajero-Díaz thanks CONACYT (México) for the Ph.D. grant and to L'Obra Social la Caixa (Spain) for the "Beca de Mobilitat Internacional" awarded in 2016. Authors are indebted to ALBA for the support given to XRD experiments carried out in the B11 line of synchrotron in Cerdanyola del Vallès (Barcelona). The support given by Dr. J. Pous for the realization of the DLS measurements is greatly appreciated. A. Heise acknowledges financial support from a Science Foundation Ireland (SFI) Principle Investigator Award 13/IA/1840(T).

\section{Supporting Information}

${ }^{1} \mathrm{H}$ NMR and ${ }^{13} \mathrm{C}$ NMR spectra of polyglobalide and copolymers. Compared GPC traces of protected and deprotected copolymers. TGA and DSC traces of copolymers. DLS plots used for $c m c$ calculations. Size distribution profiles and TEM micrographs of nanoparticles of different copolymers and polyplexes.

\section{References}

[1] A. Kumari, S.K. Yadav, S.C. Yadav, Biodegradable polymeric nanoparticles based drug delivery systems, Colloids Surf. B. Biointerfaces 75 (2010) 1-18. https://doi:10.1016/j.colsurfb.2009.09.001.

[2] C.E. Mora-Huertas, H. Fessi, A. Elaissari, Polymer-based nanocapsules for drug delivery, Int. J. $\quad$ Pharm. $385 \quad$ (2010) 113-142. https://doi:10.1016/j.ijpharm.2009.10.018.

[3] H. Seyednejad, A.H. Ghassemi, C.F. Van Nostrum, T. Vermonden, W.E. Hennink, Functional aliphatic polyesters for biomedical and pharmaceutical applications, J. Control. Release. $152 \quad$ (2011) 168-176. https://doi:10.1016/j.jconrel.2010.12.016.

[4] K.E. Washington, R.N. Kularatne, V. Karmegam, M.C. Biewer, M.C. Stefan, Recent advances in aliphatic polyesters for drug delivery applications, Wiley 
Interdiscip. Rev. Nanomedicine Nanobiotechnology $9 \quad$ (2017). https://doi:10.1002/wnan.1446.

[5] C. He, X. Zhuang, Z. Tang, H. Tian, X. Chen, Stimuli-sensitive synthetic polypeptide-based materials for drug and gene delivery, Adv. Health. Mater. 1 (2012) 48-78. https://doi:10.1002/adhm.201100008.

[6] K. Bauri, M. Nandi, P. De, Amino acid-derived stimuli-responsive polymers and their applications, Polym. Chem. 9 (2018) 1257-1287. https://doi: 10.1039/c7py02014g.

[7] J.V. González-Aramundiz, M.V. Lozano, A. Sousa-Herves, E. Fernandez-Megia, N. Csaba, Polypeptides and polyaminoacids in drug delivery, Expert Opin. Drug Deliv. 9 (2012) 183-201. https://doi:10.1517/17425247.2012.647906.

[8] C. Lavilla, M. Byrne, A. Heise, Block-sequence-specific polypeptides from $\alpha$ amino acid $\mathrm{N}$-carboxyanhydrides: synthesis and influence on polypeptide properties, $\quad$ Macromolecules $\quad 49 \quad$ (2016) 2942-2947. https://doi:10.1021/acs.macromol.6b00498.

[9] D.P. Walsh, R.D. Murphy, A. Panarella, R.M. Raftery, B. Cavanagh, J.C. Simpson, F.J. O’Brien, A. Heise, S.A. Cryan, Bioinspired star-shaped poly(Llysine) polypeptides: efficient polymeric nanocarriers for the delivery of dna to mesenchymal stem cells, Mol. Pharm. $15 \quad$ (2018) 1878-1891. https://doi:10.1021/acs.molpharmaceut.8b00044.

[10] M. Byrne, R. Murphy, A. Kapetanakis, J. Ramsey, S.-A. Cryan, A. Heise, Starshaped polypeptides: synthesis and opportunities for delivery of therapeutics, Macromol. Rapid Commun. 36 (2015) 1862-1876.

https:// doi:10.1002/marc.201500300.

[11] B.S. McAvan, M. Khuphe, P.D. Thornton, Polymer hydrogels for glutathionemediated protein release, Eur. Polym. J. 87 (2017) 468-477. https://doi:10.1016/j.eurpolymj.2016.09.032. 
[12] W. Gao, B. Xiang, T.T. Meng, F. Liu, X.R. Qi, Chemotherapeutic drug delivery to cancer cells using a combination of folate targeting and tumor microenvironmentsensitive polypeptides, Biomaterials $34 \quad$ (2013) 4137-4149. https://doi:10.1016/j.biomaterials.2013.02.014.

[13] S. Hehir, N.R. Cameron, Recent advances in drug delivery systems based on polypeptides prepared from N-carboxyanhydrides, Polym. Int. 63 (2014) 943954. https://doi:10.1002/pi.4710.

[14] A.-C. Albertsson, I.K. Varma, Aliphatic polyesters: synthesis, properties and applications, in: 2002: pp. 1-40. https://doi:10.1007/3-540-45734-8_1.

[15] C.M. Thomas, Stereocontrolled ring-opening polymerization of cyclic esters: synthesis of new polyester microstructures, Chem. Soc. Rev. 39 (2010) 165173. https://doi:10.1039/B810065A.

[16] T.E. Scheirs, J., Long, Modern polyesters: chemistry and technology of polyesters and copolyesters, John Wiley \& Sons, Ltd, Chichester, UK, 2004. https://doi:10.1002/0470090685.

[17] K.E. Uhrich, S.M. Cannizzaro, R.S. Langer, K.M. Shakesheff, Polymeric systems for controlled drug release, Chem. Rev. 99 (1999) 3181-3198. https://doi:10.1021/cr940351u.

[18] H. Schlaad, M. Antonietti, Block copolymers with amino acid sequences: Molecular chimeras of polypeptides and synthetic polymers, Eur. Phys. J. E. 10 (2003) 17-23. https://doi:10.1140/epje/e2003-00004-3.

[19] S. Caillol, S. Lecommandoux, A.-F. Mingotaud, M. Schappacher, A. Soum, N. Bryson, R. Meyrueix, Synthesis and self-assembly properties of peptidepolylactide block copolymers, Macromolecules 36 (2003) 1118-1124. https://doi:10.1021/Ma021187c.

[20] M. Gotsche, Amino-termined poly(L-lactide)s as initiators for the polymerization of $N$-carboxyanhydrides: synthesis of poly(L-lactide)-block-poly( $\alpha$-amino acid)s, 
Macromol. Chem. Phys. $196 \quad$ (1995) 3891-3903. https://doi.org/10.1002/macp.1995.021961203.

[21] H.R. Kricheldorf, K. Hauser, Polylactones. 55. A-B-A triblock copolymers of various polypeptides. Syntheses involving 4-aminobezoyl-terminated poly( $\varepsilon^{-}$ caprolactone) as B block, Biomacromolecules 2 (2001) 1110-1115. https:// doi:10.1021/bm0100561.

[22] Y.F. Fan, G. Chen, J. Tanaka, T. Tateishi, L-Phe end-capped poly(L-lactide) as macroinitiator for the synthesis of poly(L-lactide)-b-poly(L-lysine) block copolymer, Biomacromolecules 6 (2005) 3051-3056. https://doi:10.1021/bm050368u.

[23] M. Schappacher, A. Soum, S.M. Guillaume, Synthesis of polyester-polypeptide diblock and triblock copolymers using amino poly( $\varepsilon$-caprolactone) macroinitiators, $\quad$ Biomacromolecules $\quad 7 \quad$ (2006) 1373-1379. https://doi:10.1021/bm060008m.

[24] S. Motala-Timol, D. Jhurry, J. Zhou, A. Bhaw-luximon, G. Mohun, H. Ritter, Amphiphilic poly(L-lysine-b-caprolactone) block copolymers: synthesis, characterization, and solution properties, Macromolecules 41 (2008) 5571-5576. https://doi:10.1021/ma800917c.

[25] H. Arimura, Y. Ohya, T. Ouchi, The formation of biodegradable polymeric micelles from newly synthesized poly(aspartic acid)-block-polylactide AB-type diblock copolymers, Macromol. Rapid Commun. 25 (2004) 743-747. https://doi:10.1002/marc.200300259.

[26] J.A. Wilson, Z. Ates, R.L. Pflughaupt, A.P. Dove, A. Heise, Polymers from macrolactones: from pheromones to functional materials, Prog. Polym. Sci. 91 (2019) 29-50. https://doi:10.1016/j.progpolymsci.2019.02.005.

[27] J. Liu, Z. Jiang, S. Zhang, C. Liu, R.A. Gross, T.R. Kyriakides, W.M. Saltzman, Biodegradation, biocompatibility, and drug delivery in poly ( $\omega$-pentadecalactone- 
co-p-dioxanone) copolyesters, Biomaterials 32 (2011) 6646-6654. https://doi:10.1016/j.biomaterials.2011.05.046.

[28] J.C. Chen, J.Z. Li, J.H. Liu, L.Q. Xu, Amphiphilic poly(ethylene glycol)-bpoly(ethylene brassylate) copolymers: One-pot synthesis, self-assembly, and controlled drug release, Chinese Chem. Lett. 26 (2015) 1319-1321. https://doi:10.1016/j.cclet.2015.05.050.

[29] B. Liu, X. Zhang, Y. Chen, Z. Yao, Z. Yang, D. Gao, Q. Jiang, J. Liu, Z. Jiang, Enzymatic synthesis of poly( $\omega$-pentadecalactone-co-butylene-co-3,3'dithiodipropionate) copolyesters and self-assembly of the PEGylated copolymer micelles as redox-responsive nanocarriers for doxorubicin delivery, Polym. Chem. 6 (2015) 1997-2010. https://doi:10.1039/c4py01321b.

[30] L. Xu, J. Chen, B. Weng, J. Liu, J. Li, Synthesis and self-assembly of four-armed star copolymer based on poly(ethylene brassylate) hydrophobic block as potential drug carries, J. Nanoparticle Res. 18 (2016) 1-9. https://doi:10.1007/s11051-016-3446-6.

[31] E. Tinajero-Díaz, A. Martínez de llarduya, S. Muñoz-Guerra, Synthesis and properties of diblock copolymers of $\omega$-pentadecalactone and $\alpha$-amino acids, Eur. Polym. J. 116 (2019) 169-179. https://doi:10.1016/j.eurpolymj.2019.04.009.

[32] F. Tasaka, H. Miyazaki, Y. Ohya, T. Ouchi, Synthesis of comb-type biodegradable polylactide through depsipeptide-lactide copolymer containing serine residues, Macromolecules $32 \quad$ (1999) 6386-6389. https://doi:10.1021/ma990766n.

[33] J.H. Jeong, Y. Byun, T.G. Park, Synthesis and characterization of poly(L-lysine)g-poly(D,L-lactic-co-glycolic acid) biodegradable micelles, J. Biomater. Sci. Polym. Ed. 14 (2003) 1-11. https://doi:10.1163/15685620360511100.

[34] D.J. Price, M. Khuphe, R.P.W. Davies, J.R. McLaughlan, N. Ingram, P.D. Thornton, Poly(amino acid)-polyester graft copolymer nanoparticles for the acid- 
mediated release of doxorubicin, Chem. Commun. 53 (2017) 8687-8690. https://doi:10.1039/c7cc04504b.

[35] R. Langer, M. Poh, N. Lotan, J.S. Hrkach, P. Colombo, G. Caponetti, B. Kriwet, Microparticles of novel branched copolymers of lactic acid and amino acids: preparation and characterization, J. Pharm. Sci. 88 (2002) 136-141. https://doi:10.1021/js970457f.

[36] J.S. Hrkach, J. Ou, N. Lotan, R. Langer, Synthesis of Poly(L-lactic acid-co-Llysine) graft copolymers, Macromolecules $28 \quad$ (1995) 4736-4739. https://https://doi:10.1021/ma00117a055.

[37] B. Nottelet, A. El Ghzaoui, J. Coudane, M. Vert, Novel amphiphilic poly(عcaprolactone)-g-poly(L-lysine) degradable copolymers, Biomacromolecules 8 (2007) 2594-2601. https://doi:10.1021/bm700449c.

[38] C. Jérôme, P. Lecomte, Recent advances in the synthesis of aliphatic polyesters by ring-opening polymerization, Adv. Drug Deliv. Rev. 60 (2008) 1056-1076. https://doi:10.1016/j.addr.2008.02.008.

[39] a) J. Wilson, S.A. Hopkins, P.M. Wright, A.P. Dove Synthesis and postpolymerization modification of one-pot $\omega$-pentadecalactone block-like copolymers, Biomacromolecules 16, (2015), 3191-3200. https://doi: 10.1021/acs.biomac.5b00862; b) P. Bexis, A.W. Thomas, C.A. Bell, A.P. Dove, Synthesis of degradable poly(e-caprolactone)-based graft copolymers via a "grafting-from" approach, Polym. Chem. 7 (2016) 7126-7134. https://doi:10.1039/c6py01674j.

[40] a) K.S. Bisht, L.A. Henderson, R.A. Gross, D.L. Kaplan, G. Swift, Enzymecatalyzed ring-opening polymerization of $\omega$-pentadecalactone, Macromolecules 30 (2002) 2705-2711. https://doi:10.1021/ma961869y; b) A. Kumar, B. Kalra, A. Dekhterman, R.A. Gross, Efficient ring-opening polymerization and copolymerization of $\varepsilon$-caprolactone and $\omega$-pentadecalactone catalyzed by 
candida antartica Lipase B, Macromolecules 33 (2002) 6303-6309. https://doi:10.1021/ma000344+.

[41] a) M. Bouyahyi, R. Duchateau, Metal-based catalysts for controlled ring-opening polymerization of macrolactones: high molecular weight and well-defined copolymer architectures, Macromolecules $47 \quad$ (2014) 517-524. https://doi:10.1021/ma402072t; b) M.P.F. Pepels, I. Hermsen, G.J. Noordzij, R. Duchateau, Molecular structure-catalytic activity relationship in the ring-opening polymerization of (macro)lactones, Macromolecules 49 (2016) 796-806. https://doi:10.1021/acs.macromol.5b02391.

[42] I. Van Der Meulen, M. De Geus, H. Antheunis, R. Deumens, E.A.J. Joosten, C.E. Koning, A. Heise, Polymers from functional macrolactones as potential biomaterials: enzymatic ring opening polymerization, biodegradation, and biocompatibility, $\quad$ Biomacromolecules $\quad 9 \quad$ (2008) 3404-3410. https://doi:10.1021/bm800898c.

[43] Z. Ates, A. Heise, Functional films from unsaturated poly(macrolactones) by thiol-ene cross-linking and functionalisation, Polym. Chem. 5 (2014) 2936. https://doi:10.1039/c3py01679j.

[44] A. Heise, S.D. Kimmins, C. Kearney, T.E. da Silva, D. Olvera, S.-A. Cryan, F.C.S. de Oliveira, D.J. Kelly, M.J. Sawkins, G.P. Duffy, Direct UV-triggered thiol-ene cross-linking of electrospun polyester fibers from unsaturated poly(macrolactone)s and their drug loading by solvent swelling, $\begin{array}{lllll}\text { Biomacromolecules } & 18 & \text { (2017) } & \text { 4292-4298. }\end{array}$ doi:10.1021/acs.biomac.7b01335.

[45] Z. Ates, F. Audouin, A. Harrington, B. O'Connor, A. Heise, Functional brushdecorated poly(globalide) films by ARGET-ATRP for bioconjugation, Macromol. Biosci. 14 (2014) 1600-1608. https://doi:10.1002/mabi.201400282.

[46] W.H. Daly, D. Poché, The preparation of $N$-carboxyanhydrides of $\alpha$-amino acids using bis(trichloromethyl)carbonate, Tetrahedron Lett. 29 (1988) 5859-5862. 
https://doi:10.1016/S0040-4039(00)82209-1.

[47] G.J.M. Habraken, M. Peeters, C.H.J.T. Dietz, E. Koning, A. Heise, How controlled and versatile is $\mathrm{N}$-carboxyanhydride (NCA) polymerization at $0{ }^{\circ} \mathrm{C}$ ? effect of temperature on homo-, block and graft (co) polymerization, Polym.Chem. (2010) 514-524. https://doi:10.1039/b9py00337a.

[48] V. Darcos, S. Antoniacomi, C. Paniagua, J. Coudane, Cationic polyesters bearing pendent amino groups prepared by thiol-ene chemistry, Polym. Chem. 3 (2012) 362-368. https://doi:10.1039/C1PY00414J.

[49] Y.L. Tu, C.-C. Wang, C.-Y. Chen, Synthesis and characterization of a poly(GMA)-graft-poly(Z-L-lysine) graft copolymer with a rod-like structure, J. Polym. Sci. Part A Polym. Chem. 47 (2009) 4655-4669. https://doi:10.1002/pola.

[50] J. Watanabe, I. Uematsu, Anomalous properties of poly( $\gamma$-benzyl-L-glutamate) film composed of unusual 7/2 helices, Polymer 25 (1984) 1711-1717. https://doi:10.1016/0032-3861(84)90242-8.

[51] J. Babin, J. Rodriguez-Hernandez, S. Lecommandoux, H.-A. Klok, M.-F. Achard, Self-assembled nanostructures from peptide-synthetic hybrid block copolymers: complex, stimuli-responsive rod-coil architectures, Faraday Discuss. 128 (2005) 179-192. https://doi:10.1039/B403203A.

[52] S. Lecommandoux, M. Achard, J.F. Langenwalter, H. Klok, Self-assembly of rodcoil diblock oligomers based on $\alpha$-helical peptides, Macromolecules 34 (2001) 9100-9111. https://doi:10.1021/ma010940j.

[53] P. Papadopoulos, G. Floudas, H.A. Klok, I. Schnell, T. Pakula, Self-assembly and dynamics of poly( $\gamma$-benzyl-L-glutamate) peptides, Biomacromolecules 5 (2004) 81-91. https://doi:10.1021/bm034291q.

[54] Y. Liu, W. Wang, J. Yang, C. Zhou, J. Sun, pH-sensitive polymeric micelles triggered drug release for extracellular and intracellular drug targeting delivery, Asian J. Pharm. Sci. 8 (2013) 159-167. https://doi:10.1016/j.ajps.2013.07.021. 
[55] D. Ulkoski, C. Scholz, Impact of cationic charge density and PEGylated poly(amino acid) tercopolymer architecture on their use as gene delivery vehicles. Part 1: synthesis, self-assembly, and DNA complexation, Macromol. Biosci. 18 (2018) 1800108. https://doi:10.1002/mabi.201800108. 